\title{
Ancient Aqueous Environments at Endeavour Crater, Mars
}

Authors: R.E. Arvidson ${ }^{1}$, S.W. Squyres ${ }^{2}$, J.F. Bell III ${ }^{3}$, J. G. Catalano ${ }^{1}$, B.C. Clark ${ }^{4}$, L.S. Crumpler ${ }^{5}$, P.A. de Souza Jr. ${ }^{6}$, A.G. Fairén ${ }^{2}$, W.H. Farrand ${ }^{4}$, V.K. Fox ${ }^{1}$, R. Gellert ${ }^{7}$, A. Ghosh ${ }^{8}$, M.P. Golombek ${ }^{9}$, J.P. Grotzinger $^{10}$, E. A. Guinness ${ }^{1}$, K. E. Herkenhoff ${ }^{11}$, B. L. Jolliff ${ }^{1}$, A. H. Knoll ${ }^{12}$, R. Li $^{13}$, S.M.

McLennan $^{14}$,D. W. Ming ${ }^{15}$, D.W. Mittlefehldt ${ }^{15}$, J.M. Moore ${ }^{16}$, R. V. Morris ${ }^{15}$, S. L. Murchie ${ }^{17}$, T.J.

Parker $^{9}$, G. Paulsen ${ }^{18}$, J.W. Rice ${ }^{19}$, S.W. Ruff ${ }^{3}$, M. D. Smith ${ }^{20}$, M. J. Wolff ${ }^{4}$

Affiliations:

${ }^{1}$ Dept. Earth and Planetary Sci., Washington University in Saint Louis, St. Louis, MO, 63130, USA.

${ }^{2}$ Dept. Astronomy, Cornell University, Ithaca, NY, 14853, USA.

${ }^{3}$ School of Earth and Space Exploration, Arizona State University, Tempe, AZ 85287, USA.

${ }^{4}$ Space Science Institute, Boulder, CO 80301, USA.

${ }^{5}$ New Mexico Museum of Natural History \& Science, Albuquerque, NM 87104, USA.

${ }^{6}$ CSIRO Computational Informatics, Hobart 7001 TAS, Australia.

${ }^{7}$ Department of Physics, University of Guelph, Guelph, ON, N1G 2W1, Canada.

${ }^{8}$ Tharsis Inc., Gaithersburg MD 20877, USA.

${ }^{9}$ Jet Propulsion Laboratory, California Institute of Technology, Pasadena, CA 91109, USA.

${ }^{10}$ Division of Geological and Planetary Sciences, Caltech, Pasadena, CA 91125, USA.

${ }^{11}$ U.S. Geological Survey, Astrogeology Science Center, Flagstaff, AZ 86001, USA.

${ }^{12}$ Botanical Museum, Harvard University, Cambridge MA 02138, USA.

${ }^{13}$ Dept. of Civil \& Env. Eng. \& Geodetic Science, Ohio State University, Columbus, OH 43210, USA.

${ }^{14}$ Dept. of Geosciences, State University of New York, Stony Brook, NY 11794, USA.

${ }^{15}$ ARES, NASA Johnson Space Center, Houston, TX 77058, USA.

${ }^{16}$ NASA Ames Research Center, Moffett Field, CA 94035, USA.

${ }^{17}$ Applied Physics Laboratory, Laurel, MD, 20723, USA.

${ }^{18}$ Honeybee Robotics \& Spacecraft Mechanisms Corporation, Pasadena, CA 91103, USA.

${ }^{19}$ Planetary Science Institute, Tucson, AZ 85719, USA.

${ }^{20}$ NASA Goddard Space Flight Center, Greenbelt, MD, 20771, USA.

Submitted to Science

Online Research Article

Submitted: $11 / 04 / 13$

Revised: $12 / 8 / 13$ 


\begin{abstract}
:
Opportunity has investigated in detail rocks on the rim of the Noachian age Endeavour Crater, where orbital spectral reflectance signatures indicate the presence of $\mathrm{Fe}^{+3}$-rich smectites. The signatures are associated with fine-grained, layered rocks containing spherules of diagenetic or impact origin. The layered rocks are overlain by breccias and both units are cut by calcium sulfate veins precipitated from fluids that circulated after the Endeavour impact. Compositional data for fractures in the layered rocks suggest formation of Al-rich smectites by aqueous leaching. Evidence is thus preserved for water-rock interactions before and after the impact, with aqueous environments of slightly acidic to circum-neutral $\mathrm{pH}$ that would have been more favorable for prebiotic chemistry and microorganisms than those recorded by younger sulfaterich rocks at Meridiani Planum.
\end{abstract}

\title{
Main Text:
}

\section{Introduction.}

The Mars Exploration Rover Opportunity has been exploring Endeavour Crater, an impact crater $\sim 22 \mathrm{~km}$ in diameter formed in ancient Noachian materials, since August 2011 (1). Opportunity arrived at Cape York, an eroded segment of Endeavour's rim, where the rover traversed from the younger Burns formation sulfate-rich sandstones onto the older rim rocks (2) (Fig. 1). The rover initially traversed onto the southern tip of Cape York, named Spirit Point, where impact breccias were detected and characterized (1). After traversing along the western side of Cape York and spending the Martian winter near its northern end, Opportunity traversed back southward along the eastern side of Cape York when spring arrived.

Observations from the Mars Reconnaissance Orbiter's Compact Imaging Spectrometer for Mars (CRISM) $(3,4)$, acquired in an along track oversampled (ATO) mode to sharpen spatial 
details, were used to identify and map a $\mathrm{Fe}^{+3}$-rich smectite mineral locality in an area on the eastern side of Cape York called Matijevic Hill (5) (Fig. 1). Opportunity and its Athena instrument payload $(6,7)$ were then used to investigate this area in detail for a total of 200 sols (8) to determine the source of this mineral signature and implications for past environmental conditions (Fig. 1).

\section{CRISM Observations.}

An extensive ensemble of standard mode CRISM data with $\sim 18 \mathrm{~m} /$ pixel spatial resolution have been acquired over Endeavour Crater and its rim segments since 2006 to help identify areas that expose minerals formed in aqueous environments $(9,10,11)$. CRISM observations using the ATO mode were acquired beginning in 2010 over Cape York to identify and map aqueous minerals in detail so that Opportunity could then be directed to those localities to make groundbased observations of the relevant deposits. The CRISM ATO data were collected by gimbaling the instrument optical system to space the normally $\sim 18 \mathrm{~m}$ pixels (projected onto the ground) to a few meters apart in the along-track direction. Damped least squares processing techniques were then used to sharpen the spatial resolution to $9 \mathrm{~m} /$ pixel in this direction (Supplementary Materials). Because Cape York is approximately aligned along the MRO ground track this approach allowed identification of outcrops at a much finer spatial scale than was possible with previous observations. Using a first-principles approach to model the atmospheric gases, aerosols, and surface scattering behavior, CRISM data for each wavelength band were reduced to surface single scattering albedo (SSA), a parameter that is independent of lighting and viewing conditions (Supplementary Materials). For this study the retrieved single scattering albedos were recast to spectral radiance coefficients using the lighting and viewing conditions for laboratory 
data acquired with the Brown University RELAB spectrometer system. This allowed direct spectral feature and magnitude comparisons between RELAB and CRISM data.

Retrieved SSA spectra $(0.45$ to $2.5 \mu \mathrm{m})$ were examined interactively for all of Cape York and surrounding plains, along with use of standard band depth mapping to search for evidence of clay mineral signatures. Results show that there is one small region, located on the Endeavour Crater side of Cape York on Matijevic Hill, that shows 2.28 and $2.39 \mu \mathrm{m} \mathrm{Fe-OH}$ combination absorptions diagnostic of an $\mathrm{Fe}^{+3}$-rich smectite best matched by the mineral nontronite (12) (Fig. 2). The locations exhibiting these features were mapped using $>1.0 \%$ absorption band depth criteria (Fig. 1). The $\sim 1.9 \mu \mathrm{m}$ band depth for the average spectrum for this location is indistinguishable from the average spectrum for all of Cape York, implying a high degree of desiccation of the interlayer water $(16,17)$ (Supplementary Materials). The lack of $\sim 1.4 \mu \mathrm{m}$ absorption is also consistent with substantial desiccation. Further, the 2.28 and $2.39 \mu \mathrm{m}$ absorptions are shallow, even compared to laboratory-derived spectra of a mix of anhydrous basalt and $5 \%$ by weight of $\mathrm{Fe}^{+3}$-rich smectite $(18,19)$ (Fig. 2). This implies that the $\mathrm{Fe}^{+3}$-rich smectite on Cape York likely occurs at only a few weight percent of the exposed material.

\section{Opportunity Observations.}

Overview: Opportunity was commanded to turn uphill and start a detailed investigation of the rocks on Matijevic Hill at the location where CRISM data showed the $\mathrm{Fe}^{+3}$-rich smectite signature (Fig. 1). These localities correspond to rocks subsequently named the Matijevic formation that range from light toned, planar outcrops with a discontinuous of darker veneers, to erosionally resistant ridges with high concentrations of small spherules (Figs. 3-4). In a few locations, apparent bedding exposed in cross section is expressed as millimeter- to centimeterscale layers (Fig. 5). The Matijevic formation rocks are fine grained, with subrounded particles 
ranging from $\sim 0.3 \mathrm{~mm}$ in size to below the limit of Microscopic Imager (MI) resolution (Supplementary Materials). Rare dark particles are present, with shapes that range from angular to sub-rounded. The energy/volume required to grind into spherule-free exposures of these rocks with the rover's Rock Abrasion Tool (RAT) is $\sim 2.8 \mathrm{~J} / \mathrm{mm}^{3}$, similar to soft sulfate-rich sandstones elsewhere at the Opportunity site (20) and to some of the weakest rocks found by the rover Spirit (21).

The elemental composition of most Matijevic formation rocks as determined by the Alpha Particle X-Ray Spectrometer (APXS) (Table 1) is similar to average Martian soil (i.e., basaltic) (22), similar to average Martian upper crust on a S- and Cl-free basis (23), and slightly higher in $\mathrm{Si}$ and $\mathrm{Al}$ and lower in Fe than the Shoemaker formation impact breccias that make up most of Cape York (1). Analysis of photon scattering peaks (24) in APXS data from Matijevic materials does not reveal excess light elements within detection limits. This observation places an upper limit of $\sim 5$ wt. $\% \mathrm{H}_{2} \mathrm{O}$ in the rock. The inferred lack of hydration is consistent with the CRISM-based $\mathrm{Fe}^{+3}$-rich smectite detection that shows $\mathrm{Fe}-\mathrm{OH}$ combination bands at 2.28 and $2.39 \mu \mathrm{m}$, but lacking evidence for $1.4-$ or $1.9-\mu \mathrm{m}$ bands indicative of extensive interlayer water (Supplementary Materials).

The $\mathrm{Fe}^{+3}$-rich smectite signature seen in CRISM data likely results from the presence of the veneers because these deposits are enriched in elements $(\mathrm{Zn}, \mathrm{S}, \mathrm{Cl}, \mathrm{Br})$ that are mobile under aqueous conditions and the signature from CRISM data maps to locations where veneers are present (Figs. 1, 3). Pancam spectra show that where dust has been brushed away using the Rock Abrasion Tool (RAT) the veneers exhibit a subtle absorption centered over the $0.934 \mu \mathrm{m}$ band (Fig. 6). This feature is consistent with but not uniquely indicative of the presence of a $\mathrm{Fe}^{+3}$-rich smectite electronic transition absorption (12). An equivalent feature is not apparent in CRISM 
spectra retrieved for the CRISM S data $(\sim 0.45$ to $1.0 \mu \mathrm{m})$ for the region where the 2.28 and 2.39 $\mu \mathrm{m}$ absorptions are present. This is likely because of the subtle nature of the $0.934 \mu \mathrm{m}$ absorption and obscuration by wind-blown dust that dominates spectra for these wavelengths in most areas of Mars, including Endeavour's rim segments.

Spherules: The spherules that are present in many Matijevic formation rocks are found in concentrations that range up to $\sim 40$ percent by volume, with highest values at the Kirkwood locality (Fig. 7). Spherules are typically $2-3 \mathrm{~mm}$ in diameter, with $\sim 5 \mathrm{~mm}$ maximum diameter. Wind erosion of the spherules has exposed concentric structures, with resistant outer shells, less resistant interiors that are visually similar to the surrounding matrices, and irregular and resistant internal structures. Spherules are mostly matrix-supported, even at the Kirkwood locality, although some are in contact with one another. Kirkwood lacks laminar bedding, although roughly horizontal partings accentuated by wind erosion are weakly expressed. Spherule-rich outcrops like Kirkwood are resistant to erosion relative to materials around them, and thus stand out in positive relief. The RAT specific grind energy of Kirkwood is $\sim 23 \mathrm{~J} / \mathrm{mm}^{3}, \sim 8$ times higher than that of spherule-free Matijevic formation rocks.

Spherules exhibit subtle compositional differences compared to the matrix in which they are embedded (Fig. 8). $\mathrm{FeO}_{\mathrm{T}}$ increases with increasing spherule abundance, whereas $\mathrm{CaO}, \mathrm{Al}_{2} \mathrm{O}_{3}$, and $\mathrm{MnO}$ decrease. The $\mathrm{FeO}_{\mathrm{T}} / \mathrm{MnO}$ ratio varies from less than 50 in spherule-free Matijevic formation materials to more than 75 in spherule-rich targets, extrapolating to $>100$ in pure spherules. Spherules are also slightly redder in Pancam color images than the matrix in which they are embedded, and cuttings produced by RAT abrasion of dense accumulations of spherules show a subtle $0.535 \mu \mathrm{m}$ absorption in Pancam data that is consistent with the presence of finegrained iron oxides. 
Impact Breccias: Overlying the Matijevic formation is a unit that is best exposed at Copper Cliff (Figs. 1, 3, 9A). The contact at this location is planar and likely an unconformity, with an abrupt transition from the light-toned, fine-grained, orthogonally jointed Matijevic formation rocks upward into darker rock exposures in Copper Cliff with coarse, poorly sorted rock clasts and no visible jointing. MI images show Copper Cliff rocks are breccias, with clasts up to a few centimeters in size (Fig. 9B). Some spherules are present and show a decrease in abundance up section.

The elemental composition of the Copper Cliff breccias (Table 1) differs from that of Shoemaker formation impact breccias found elsewhere on Cape York (1), particularly near the bottom of the section on Matijevic Hill. The lowermost target, Onaping, has higher $\mathrm{Al}_{2} \mathrm{O}_{3}$ and lower $\mathrm{FeO}_{\mathrm{T}}$ than Shoemaker formation breccias, whereas other rocks sampled that lie stratigraphically above Onaping (Vermillion Cliffs, Vermillion Lake, Maley) become increasingly similar to Shoemaker formation breccias. All of these targets have high $\mathrm{Ni}$ compared to other Shoemaker formation breccias, but similar to those of the Matijevic formation rocks.

Sulfate-Rich Veins: Both Matijevic formation rock exposures and the overlying Copper Cliff breccias locally contain narrow, light-toned fracture-filling veins (Fig. 10A). Maximum widths are $\sim 1$ centimeter, and most are much narrower. Multiple APXS measurements on dense concentrations of veins show a strong correlation of $\mathrm{CaO}$ with $\mathrm{SO}_{4}$ (Fig. 10B), in a ratio consistent with a dominance by Ca-sulfate. Pancam multispectral images of the veins show a marked downturn in reflectance from 0.934-1.009 $\mu \mathrm{m}$. This same downturn has been observed for much larger Ca-sulfate veins west of Cape York, where it was attributed to a $\mathrm{H}_{2} \mathrm{O}$ overtone feature indicative of the hydrated $\mathrm{CaSO}_{4}$ mineral gypsum $(1,25)$. 
Boxwork Fractures: In a few locations, Matijevic formation outcrops are cut by decimeter-scale boxwork fractures defined by planar fins and vertical laminae that lie parallel to quasi-orthogonal joint planes. A distinctive linear zone along one of the joint planes, named Espérance, is $\sim 0.5 \mathrm{~m}$ long, with an irregular width reaching $\sim 0.1 \mathrm{~m}$. This area was the site of an intensive measurement campaign. The bulk of the material in Espérance is brighter than the host rock, with patchy darker coatings. The chemical composition of Espérance (Table 1) is noteworthy. After partial RAT abrasion of the target Espérance6, APXS data show the lowest values of $\mathrm{FeO}_{\mathrm{T}}\left(4.4\right.$ wt.\%) and $\mathrm{CaO}\left(2.1\right.$ wt.\%), and the highest values of $\mathrm{SiO}_{2}(62.5$ wt.\%) and $\mathrm{Al}_{2} \mathrm{O}_{3}$ (15.4 wt.\%) measured by Opportunity at Meridiani Planum. In addition, Pancam images of the brightest regions of Espérance show a downturn in reflectance from 0.934-1.009 $\mu \mathrm{m}$, consistent with the presence of one or more hydrated mineral phases (e.g., hydrated silica (25)), although APXS scatter-peak ratios constrain the water content to be less than $\sim 5 \mathrm{wt} . \%$.

\section{Interpretations.}

The origin of Matijevic formation rocks is constrained, although not uniquely, by their fine-grained and locally layered character. These rocks have been observed to date only on Matijevic Hill, and thus broader geologic context for their formation is lacking. Fine-grained clastic rocks can form by impact, explosive volcanic, eolian, or fluvial/lacustrine processes, and without context we cannot distinguish confidently among these possibilities. If the deposits are an impactite, the fine-grained nature, with overlying coarse breccias, implies that they are distal ejecta from an impact that predates Endeavour, not from the Endeavour impact itself. Whatever their origin, the Matijevic formation exposes the oldest materials investigated to date by Opportunity. 
The veneers are likely the carrier of the $\mathrm{Fe}^{+3}$-rich smectite signature detected from CRISM data and are inferred to have formed either as surface deposits, or along bedding plane fractures as mildly acidic $(>5 \mathrm{pH},(26,27))$ waters were neutralized by reactions with the finely layered strata, producing a small amount of $\mathrm{Fe}^{+3}$-rich smectite and salts.

Two hypotheses and considered for the origin of the spherules: diagenetic concretions and accretionary lapilli (impact or volcanic). Textural arguments do not by themselves eliminate either hypothesis. Concretions with concentric zoning (i.e., hard exteriors) similar to those observed in Matijevic Hill spherules can form under conditions of diffusion limitation from pore waters characterized by variable $\mathrm{pH}$ and low but variable oxygen availability $(28,29,30)$. On the other hand, concentric structures are also found in some impact lapilli $(31,32)$. Spherules in Matijevic formation rocks are found dispersed through finely layered bedding (Fig. 5). Hydraulic segregation according to particle size (and hence settling velocity) during entrainment by fluids should lead to sorting and deposition of coarse particles before fine particles (33). The observed dispersion of spherules across fine bedding in Matijevic formation rocks therefore favors origin as concretions. Dense concentrations of spherules are observed at Kirkwood that fall near the high end of concretion densities found on Earth. This would require unusual bed-bybed variation in rates of fluid flow or availability of nucleation sites, which occasionally does happen on Earth during formation of concretions. Dense decimeter-thick layers of accretionary lapilli are also well documented in impact deposits and occur within a finer-grained matrix (34).

Perhaps the strongest evidence favoring a spherule origin as concretions is the difference in chemistry between the spherules and their matrix, but this difference is subtle (Fig. 8). If the spherules are concretions, they must be lightly cemented as compared to the hematite-rich concretions of the Meridiani plains (2). Extrapolating compositional data for spherule-rich rocks 
to $100 \%$ spherules suggests only about $20 \% \mathrm{FeO}_{\mathrm{T}}$ (Fig. 8). If the change in $\mathrm{FeO}_{\mathrm{T}}$ concentration reflects an increase in $\mathrm{Fe}^{+3}$, then cementation may involve a small proportion of ferric oxide or oxyhydroxide, consistent with the spectral properties of spherule cuttings. The increased $\mathrm{FeO}_{\mathrm{T}} / \mathrm{MnO}$ in spherule-rich targets is consistent with changing redox/pH conditions such that $\mathrm{Fe}^{+2}$ in solution oxidized to $\mathrm{Fe}^{+3}$ and precipitated as a thin cement, while $\mathrm{Mn}^{+2}$ continued in solution to precipitate elsewhere. Interpretation of spherules as lapilli would require layerspecific alteration during diagenesis; therefore, both hypotheses invoke groundwater flow within Matijevic formation rocks.

The rocks exposed at Copper Cliff and higher up the side of Matijevic Hill are impact breccias that probably date from the Endeavour impact event. They are either part of or are overlain by Shoemaker formation breccias exposed over much of Cape York (1), and are the stratigraphically lowest breccias examined by Opportunity to date. The spherules they contain may have been released from the Matijevic formation rocks during impact and mixed into the breccias. The different chemical compositions of the lower Copper Cliff breccias as compared to Shoemaker formation breccias also suggests some admixture of Matijevic materials, moderate aqueous alteration after emplacement, and/or a differing provenance reflected in a higher feldspathic/mafic ratio in the lithic fragments. The high Ni content suggests Ni mobilization by alteration fluids subsequent to emplacement of the breccias.

The sulfate-rich veins observed in both the Matijevic formation and at Copper Cliff formed when narrow fractures were filled by calcium sulfate precipitated from fluids generated within the underlying Noachian crust. Calcium sulfate was likely precipitated closest to the Noachian source rocks, rather than other sulfates (e.g., $\mathrm{MgSO}_{4} \bullet n \mathrm{H}_{2} \mathrm{O} ; \mathrm{FeSO}_{4} \bullet n \mathrm{H}_{2} \mathrm{O}$ ) or chlorides, because of its lower solubility in most aqueous fluids. The veins postdate the Copper 
Cliff breccias, so this aqueous activity postdates the Endeavour impact, suggesting that impactdriven hydrothermal flow could have been a factor. Centimeter-width, linear gypsum veins have also been observed adjacent to Cape York (1), and the narrower and less regular veins of Matijevic Hill could date from the same episode, although no observed geologic relationships confirm this.

The distinctive chemistry of Espérance indicates substantial aqueous alteration, particularly when viewed in the classical ternary diagram of mole fraction $\mathrm{Al}_{2} \mathrm{O}_{3}$ $\left(\mathrm{CaO}+\mathrm{Na}_{2} \mathrm{O}+\mathrm{K}_{2} \mathrm{O}\right)-\left(\mathrm{FeO}_{\mathrm{T}}+\mathrm{MgO}\right)($ Fig. 11b). In this diagram silicate minerals that plot along and below the feldspar-(FeO $\left.\mathrm{F}_{\mathrm{T}}+\mathrm{MgO}\right)$ join are igneous, whereas above the join secondary clay minerals dominate (35). Data for spherule-rich rocks plot toward the $\mathrm{FeO}_{\mathrm{T}}+\mathrm{MgO}$ apex whereas data for veins plot toward the $\mathrm{CaO}+\mathrm{Na}_{2} \mathrm{O}+\mathrm{K}_{2} \mathrm{O}$ apex, consistent with compositional inferences discussed in previous paragraphs. Six APXS measurements were made on Espérance, culminating in the target Espérance6 that was partially abraded with the RAT, plus a seventh nearby point called Lihir. These data define a near-vertical trend in the diagram that is interpreted as a mixing line between typical Matijevic formation rocks and the underlying altered rock best represented by Espérance6. Results are consistent with a high concentration of an Alrich smectite. The Espérance data also show a positive correlation between $\mathrm{Al}_{2} \mathrm{O}_{3}$ and $\mathrm{SiO}_{2}$, with excess silica indicated at low $\mathrm{Al}_{2} \mathrm{O}_{3}$ values (Table 1). A mineral assemblage that includes substantial amounts of Al-rich smectite and a siliceous phase or phases provides compelling evidence for substantial aqueous alteration. In addition, the loss of iron implies that the fluid was reducing because ferric oxides would have been generated under oxidizing conditions at all but very low $\mathrm{pH}$ values. 
The boxwork fractures at Espérance and elsewhere are similar to the parallel slab-like foliations commonly associated with mineral volume changes at uniform depths on rock exteriors, and could have presented pathways for fluid flow. The strong localization of alteration along these fractures indicates that the alteration occurred in place, after the fractures formed.

The events recorded at Matijevic Hill imply Martian an aqueous environment quite different from those that produced the overlying sulfate-rich Burns formation sandstones. Deposition began with fluvial, eolian, distal impact or explosive volcanic emplacement of layered, fine-grained deposits that dominate the Matijevic formation. These materials underwent minor aqueous modification that generated $\mathrm{Fe}^{+3}$-rich smectite and locally more intense alteration by enhanced fluid flow along fractures that generated relatively high concentrations of clay minerals and hydrated silica-rich materials. Breccias were subsequently emplaced above the Matijevic formation, probably by the Endeavour impact. Subsequently, post-impact fluid circulation, perhaps including impact-triggered hydrothermal flow, led to precipitation of Casulfate veins in fractures that cut through both the Matijevic formation and the overlying Copper Cliff breccias.

The aqueous modification of Matijevic materials provides evidence for the earliest episode of water activity documented by Opportunity. In particular, the unusual chemistry of Espérance points to an early period of localized intense alteration under fluid-dominated, nearneutral to modestly low $\mathrm{pH}$ and reducing conditions that would, at least transiently, have been more favorable to life or prebiotic chemistry (41) than the very low acidic conditions recorded by younger Burns formation sulfate-rich sandstones.

\section{References and Notes:}

1. S.W. Squyres et al., Science 336, 570 (2012).

2. S.W. Squyres, A.H. Knoll, Earth Planet. Sci. Lett. 240, 1 (2005). 
3. S. L. Murchie et al., JGR-Planets 112 E05S03 (2007).

4. CRISM is a hyperspectral imager that operates from 0.362 to $1.053 \mu \mathrm{m}$ (S data range) and 1.002 to $3.920 \mu \mathrm{m}$ (L data range) (3).

5. Matijevic Hill is named to honor the late Jacob R. Matijevic, one of the engineers most responsible for development of NASA Mars rovers, including Spirit and Opportunity.

6. S.W. Squyres et al., J. Geophys. Res. 108, 8062 (2003).

7. The Miniature Thermal Emission Spectrometer (Mini-TES) Athena Payload instrument was not used for this investigation because of temperature-related instrument degradation and optically thick dust on its mirrors that accumulated during the 2007 global dust storm. The Mössbauer Spectrometer was not used because of the decay of its ${ }^{57}$ Co radiation source. The mast-based Pancam camera, and the arm-mounted Microscopic Imager (MI), Alpha Particle X-Ray Spectrometer (APXS), and Rock Abrasion Tool (RAT) were all utilized in characterizing materials on Matijevic Hill. In addition the mast-based Navcam and bodymounted Hazcam engineering cameras were used for contextual observations.

8. A sol is defined as one Martian solar day.

9. J. J. Wray et al., Geophys. Res. Lett. 36, L21201 (2009).

10. E. Z. Noe Dobrea et al., Geophys. Res. Lett. 39, L23201 (2012).

11. Previous work with CRISM data acquired with the $18 \mathrm{~m} / \mathrm{pixel}$ nominal resolution were used to infer the presence of diagnostic Fe-Mg smectite (mix of nontronite and saponite) spectral bands at 1.9, 2.3, and $2.4 \mu \mathrm{m}$ on Cape Tribulation, a larger rim segment to the south of Cape York $(9,10)$, and hinted at their presence on Cape York (9). Additional analysis of the Cape York detection shows that it is associated with column-dependent noise and not a real detection.

12. Nontronite (dioctahedral $\mathrm{Fe}^{+3}$-rich) is one of a family of smectite clay minerals that includes dioctahedral montmorillonite (Al-rich) and trioctahedral saponite (Mg-rich). Nontronite is a common terrestrial weathering product of basaltic rocks. Nontronite spectra are controlled by the presence of $\mathrm{Fe}^{+3}$ electronic transition absorptions centered at $\sim 0.43,0.62$, and 0.93 to $0.94 \mu \mathrm{m}$, an $\mathrm{OH}$ stretch overtone absorption at $\sim 1.4 \mu \mathrm{m}$, an $\mathrm{OH}$ stretch and $\mathrm{H}-\mathrm{O}-\mathrm{H}$ bending mode combination band at $\sim 1.9 \mu \mathrm{m}$, and $\mathrm{OH}$ stretch and $\mathrm{Fe}-\mathrm{OH}$ bending mode combination bands at 2.28 and $2.39 \mu \mathrm{m}$ for nontronite (13). See (14) for an overview of clay mineral formation and (15) for initial discoveries on Mars.

13. B. L. Ehlmann et al., Mineralogy and chemistry of altered Icelandic basalts: Application to clay mineral detection and understanding aqueous environments on Mars. JGR-Planets 117, E00J16 (2012).

14. B. L. Ehlmann et al., Subsurface water and clay mineral formation during the early history of Mars. Nature 479, 53-60 (2011).

15. F. Poulet et al., Phyllosilicates on Mars and implications for early Martian climate. Nature 438, 623-627 (2005).

16. R. V. Morris et al., Visible and near-IR reflectance spectra of Mars analogue materials under arid conditions for interpretation of Martian surface mineralogy. Abstracts from the 42nd Lunar and Planetary Science Conference, 1608, 2757 (2011).

17. R. V. Morris et al. (16) show results from a series of dehydration experiments for nontronite in which the interlayer water was progressively removed. This greatly reduced the 1.4 and $1.9 \mu \mathrm{m}$ bands whereas the longer wavelength $\mathrm{Fe}-\mathrm{OH}$ combination bands remained largely unchanged. 
18. B. L. Ehlmann et al., Abstracts from the First Moscow Solar System Symposium, How much clay is on Mars? Lessons from visible/near-infrared (VNIR) and XRD study of hydrated silicate mineral assemblages in altered basalts from Iceland., Space Research Institute of Russian Academy of Sciences, Moscow (October 2010).

19. B. L. Ehlmann et al. (18) present RELAB-based spectral data for basaltic sand and basaltic sand mixed with varying weight percentages of clay-sized nontronite, together with a relationship between band depth and amount of nontronite in the sample. Scaling from this relationship indicates that the nontronite on Matijevic Hill occurs at only a few weight percentage level. RELAB data were acquired in a bidirectional mode with an incidence angle of $0^{\circ}$ and an emission angle of $30^{\circ}$. Data are presented as spectral radiance coefficients which are defined as the spectral radiance from the target divided by the spectral radiance for a perfectly reflecting Lambertian surface with both the target and standard illuminated at the same incidence angle.

20. S.W. Squyres et al., J. Geophys. Res. 111, E02S11 (2006).

21. R.E. Arvidson et al., Science 306, 1730 (2004).

22. A.S. Yen et al., Nature 436, 49 (2005).

23. S.R. Taylor, S.M. McLennan, Planetary Crusts, Their Composition, Origin and Evolution (Cambridge, 2009).

24. J. L. Campbell et al., J. Geophys. Res. 113, E06S11 (2008).

25. Rice, M. et al., Icarus 205, 375 (2010).

26. J. G. Catalano et al., JGR-Planets, doi:10.1002/JGRE.20161 (2013).

27. Based on geochemical modeling J. G. Catalano et al. (25) showed that nontronite formation without extensive leaching of other cations will not occur below a $\mathrm{pH} \sim 5$.

28. M.A. Chan et al., Geofluids 7, 1 (2007).

29. D.B. Loope et al., Sedimentology 59, 1769 (2012).

30. J.H. Wilson et al., Chem. Geol. 312, 195 (2012).

31. G. Graup, Earth Planet. Sci. Lett. 55, 407, (1981).

32. M.A. Jirsa et al., Geo. Soc. Amer. Field Guide 24, 147, doi:10.1130/2011.0024(08) (2011).

33. P. Fralick, J. Grotzinger, L. Edgar, in Sedimentary Geology of Mars, SEPM Special Publication No. 11, 211 (2011).

34. D. Stöffler et al., Meteor. Plan. Sci. 48, 515 (2013).

35. H.W. Nesbitt, R.E. Wilson, Am. J. Sci. 292, 740 (1992).

36. A.F White, in Chemical Weathering Rates of Silicate Minerals, Reviews in Mineralogy, A. White, S. Brantley, Eds. (Mineralogical Society of America, Washington, DC, 1995), vol. 31, p. 407.

37. L.L. Griffith, E.L. Shock, J. Geophys. Res. 102, 9135 (1997).

38. J.T. Kloprogge, S. Komarneni, J.E. Amonette, Clays and Clay Minerals 47, 529 (1999).

39. L.L. Baker, D.J. Agenbroad, S.A. Wood, Meteor. Planet. Sci. 35, 31 (2000).

40. J.A. Hurowitz et al., J. Geophys. Res. 110, E07002, doi:10.1029/2004JE002391 (2005).

41. A.H. Knoll et al., Earth Planet. Sci. Lett. 240, 179 (2005).

42. A.R. Mermut, A.F. Cano, Baseline studies of the Clay Minerals Society source clays: Chemical analyses of major elements. Clays and Clay Minerals 49, 381-386 (2001).

43. K. Emmerich et al., Clay profiling: The classification of montmorillonites, Clays and Clay Minerals 57, 104-114 (2009).

44. F. Wolters et al., A comprehensive characterization of dioctahedral smectites, Clays and Clay Minerals 57, 115-133 (2009). 
45. P. C. Hansen et al., Deblurring Images (Society for Industrial and Applied Mathematics, 2006).

46. K. Stamnes, Numerically stable algorithm for discrete-ordinate-method radiative transfer in multiple scattering and emitting layered media, Appl. Opt. 27 (1988).

47. M. J. Wolff et al., JGR-Planets 114, E00D04 (2009).

48. B. Hapke, Theory of Reflectance and Emittance Spectroscopy (Cambridge Univ. Press, 2011).

49. K. N. Liou, An Introduction to Atmospheric Evolution (Academic Press, second edition, 2002).

50. K. E. Herkenhoff et al., J. Geophys. Res. 108, 8065 (2003).

51. K. E. Herkenhoff et al., J. Geophys. Res. 111, E02S04, doi:10.1029/2005JE002574 (2006).

Acknowledgements: This work was supported by NASA. The CRISM operations team at the Applied Physics Laboratory, Johns Hopkins University, and the Opportunity operations team at the Jet Propulsion Laboratory, California Institute of Technology were responsible for planning and acquiring the relevant data. The NASA Planetary Data System through the Geosciences Node (http://pds-geosciences.wustl.edu/) provides access to the CRISM and Opportunity data used in this paper.

\section{Figure Captions:}

Fig. 1. Upper left inset is a portion of a false color HiRISE image centered on Cape York. Black outlines Matijevic Hill as shown in the main figure with initial traverses accomplished by Opportunity to evaluate the geologic setting of the region for which CRISM data showed the presence of $\mathrm{Fe}^{+3}$-rich smectite. Key named locations and the Espérance target are shown, along with the location from which the sol 3132 Navcam mosaic shown in Fig. 3 was taken. Lower left shows a portion of CRISM ATO FRT0001D86B centered on Cape York and processed to 9 $\mathrm{m} /$ pixel along track and projecting RGB as 2.2, 1.8, and $1.2 \mu \mathrm{m}$ (see Supplementary Materials). The red region in the CRISM insert delineates where CRISM spectra show 2.28 and $2.39 \mu \mathrm{m}$ absorptions diagnostic of $\mathrm{Fe}^{+3}$-rich smectite. HiRISE observation ESP_032573_1775_color.jp2.

Fig. 2A. CRISM-based, continuum-removed mean spectrum for the $\mathrm{Fe}^{+3}$-rich smectite locations on Matijevic Hill, together with a laboratory spectrum for the mix of $95 \%$ basalt and $5 \%$ nontronite $(18,19)$. As explained in Supplementary Materials the increased noise level for wavelengths less than $\sim 2.2 \mu \mathrm{m}$ precludes identification of subtle metal-OH absorption features for this wavelength interval.

Fig. 2B. Continuum-removed laboratory spectra of $100 \%$ fine-grained (clay-sized) montmorillonite (Al-rich), nontronite $\left(\mathrm{Fe}^{+3}\right.$-rich), and saponite (Mg-rich) smectites are plotted. Nontronite (12) is the best spectral match to the CRISM spectrum. Saponite spectrum is from sample LASA59 in the RELAB archives at Brown University. Montmorillonite spectrum is from sample SWY-2, documented in (42).

Fig. 3. A portion of a Navcam image mosaic acquired on sol 3132 (see Fig. 1 for location on Cape York) looking to the north and northeast at recessive, bright, finely-layered Matijevic 
formation outcrops partially covered by dark veneers. Opportunity in-situ observations were acquired for the Onaping, Sandcherry, and Esperance targets, in addition to several targets at Whitewater Lake and Kirkwood (See Fig. 4). The Matijevic formation materials are overlain by impact breccias (including rocks exposed on Copper Cliff) on the upslope portion of the scene. These breccias may or may not be part of the Shoemaker formation breccias exposed over much of Cape York. Matijevic formation outcrops extend to the right and downhill of the scene for $\sim 30$ $\mathrm{m}$ whereas in the Whitewater Lake and Kirkwood areas these rocks extend only $\sim 4 \mathrm{~m}$ along the down slope direction. Stratigraphic section for the local area and surroundings is shown in the lower right. The Grasberg unit includes materials that form the bench that surrounds Cape York (1).

Fig. 4. Portion of a Pancam false color mosaic acquired between sols 3064 to 3070 of the Kirkwood (dark outcrop at bottom of figure) and Whitewater Lake (planar bright outcrops with dark veneers) areas showing the targets Azilda, Chelmsford (veneer), and the Ortiz (veins). For scale the distance between the Azilda and Ortiz targets is $\sim 60 \mathrm{~cm}$. Pancam bands L2 $(0.753 \mu \mathrm{m})$, L5 $(0.535 \mu \mathrm{m})$, and L7 $(0.432 \mu \mathrm{m})$ shown as RGB.

Fig. 5. Pancam false color view acquired on sol 3066 of fine-scale layering in the Whitewater Lake locality. Veneers have been resistant to wind erosion and enhanced the layered appearance of the outcrop. Layers are typically several millimeters thick.

Fig. 6A. Pancam false color view showing the Chelmsford veneer after brushing using the Rock Abrasion Tool. Brushed areas are $\sim 3.8 \mathrm{~cm}$ wide. Data acquired on sol 3098 .

Fig. 6B. Pancam-based spectra of undisturbed bright layer, together with Chelmsford veneer undisturbed and brushed surfaces. Note the presence of the subtle absorption associated with the Pancam data acquired on sol 3098.

Fig. 7A. Pancam false color image acquired on sol 3208 of Matijevic formation rocks at the Whitewater Lake locality, showing embedded spherules. Approximate scale across image is 40 $\mathrm{cm}$.

Fig. 7B. MI mosaic acquired on sol 3064 showing a dense concentration of spherules at the Kirkwood target and locality. Approximate scale across the scene is $5 \mathrm{~cm}$ and illumination is from the top.

Fig. 8. Oxide concentrations in spherule-bearing targets are plotted as a function of the fraction of the APXS field of view filled by spherules as determined from MI images. Error bars represent $2-\sigma$ error for precision of the measurements.

Fig. 9A. Portion of a Pancam false color mosaic acquired over sols 3137-3150, showing darktoned impact breccias of the Copper Cliff outcrop overlying lighter-toned Matijevic formation materials. The width across the dark outcrops is $\sim 1.5 \mathrm{~m}$. Location of Onaping MI mosaic shown in Fig. 9B is indicated by circle. 
Fig. 9B. MI mosaic acquired on sol 3158, showing breccia clasts, spherules, and light-toned veins in the target Onaping. Approximate scale across the image is $6 \mathrm{~cm}$ and illumination is from the top.

Fig. 10A. MI mosaic acquired on sol 3189 of the vein-rich location named "Ortiz" at the Whitewater Lake locality, merged with coregistered Pancam enhanced color data. Circles show the fields of view of four APXS measurements. Circle diameters are $3.8 \mathrm{~cm}$.

Fig. 10B. $\mathrm{CaO}$ vs. $\mathrm{SO}_{3}$ for the APXS placements on Ortiz tragets (multiple measurements were made at some locations). Error bars are relative counting statistics, $2 \sigma$.

Fig. 11A. Pancam false color view acquired on sol 3230 showing the boxwork structure and examined in detail. Circle indicates the targets Espérance6 (which was abraded with the RAT) and Lihir. Approximate scale across the scene is $70 \mathrm{~cm}$.

Fig. 11B. Ternary plot of mole fraction $\mathrm{Al}_{2} \mathrm{O}_{3}-\left(\mathrm{CaO}+\mathrm{Na}_{2} \mathrm{O}+\mathrm{K}_{2} \mathrm{O}\right)-\left(\mathrm{FeO}_{\mathrm{T}}+\mathrm{MgO}\right)$ for selected rocks from Matijevic Hill (Table 1) and other materials. Mineral compositions based on idealized stoichiometry, the field for montmorillonite based on structural formulae of 25 natural montmorillonites $(43,44)$, and average Martian crust and soils taken from (23). 


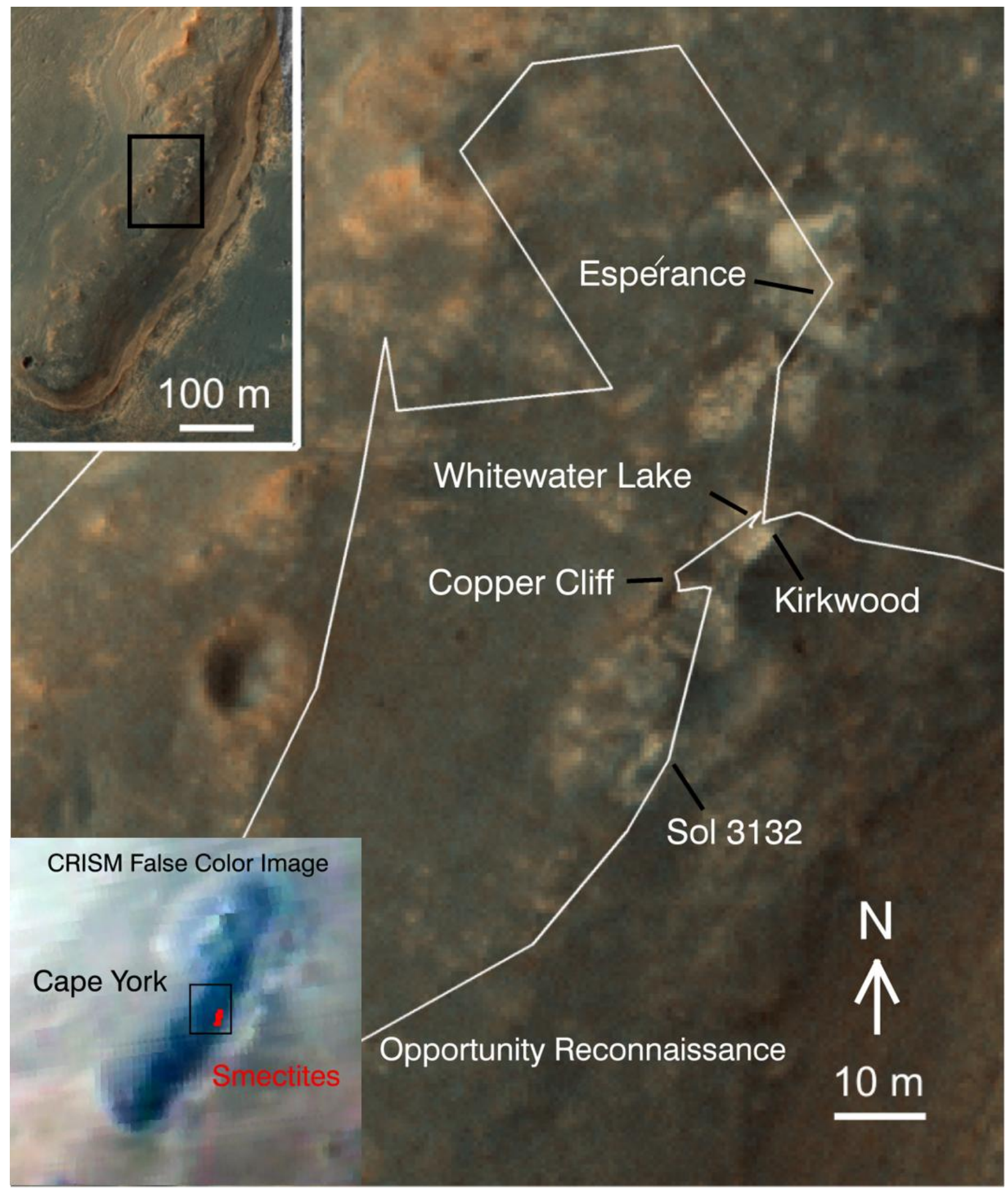

Figure 1 

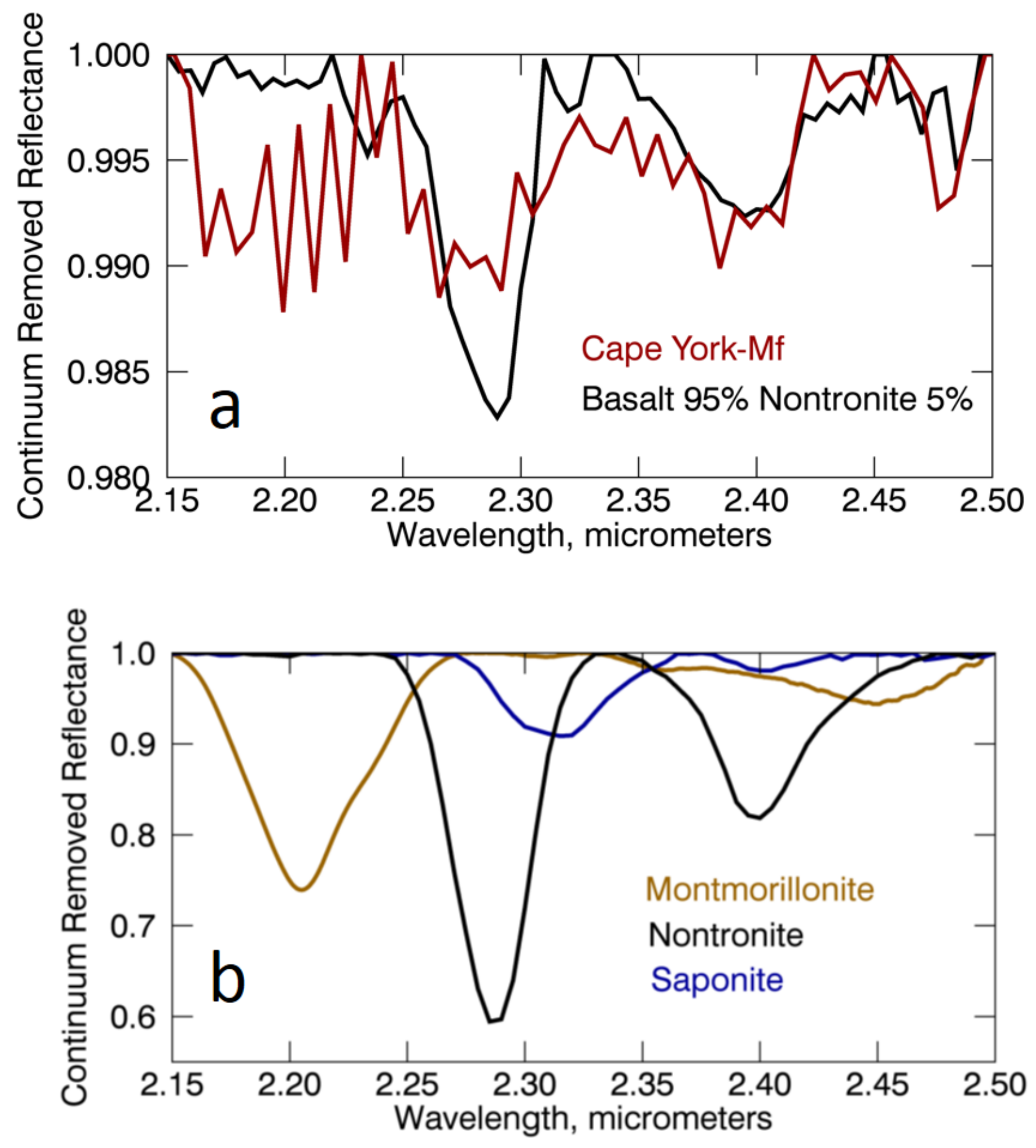

Figure 2 


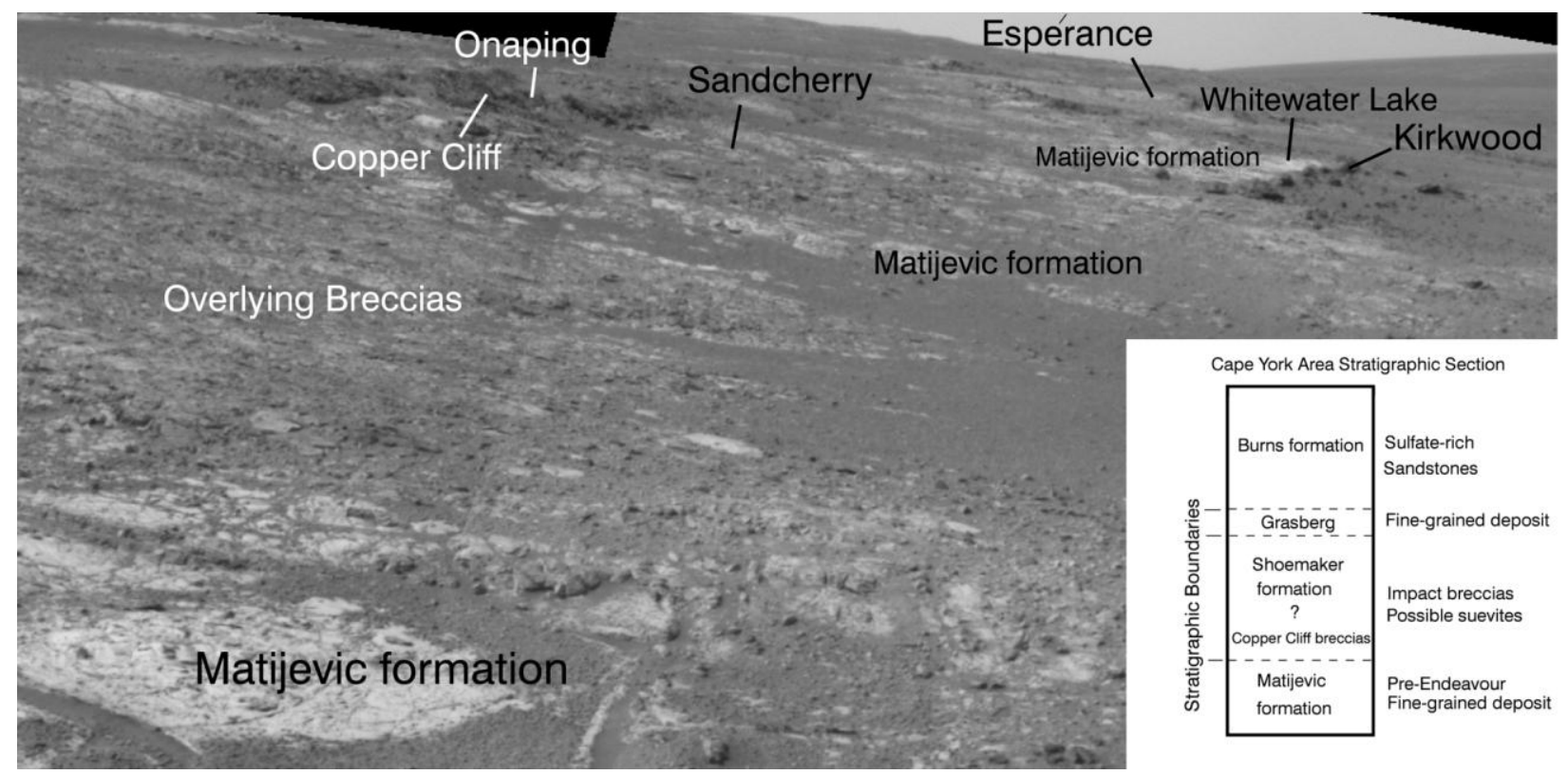

Figure 3 


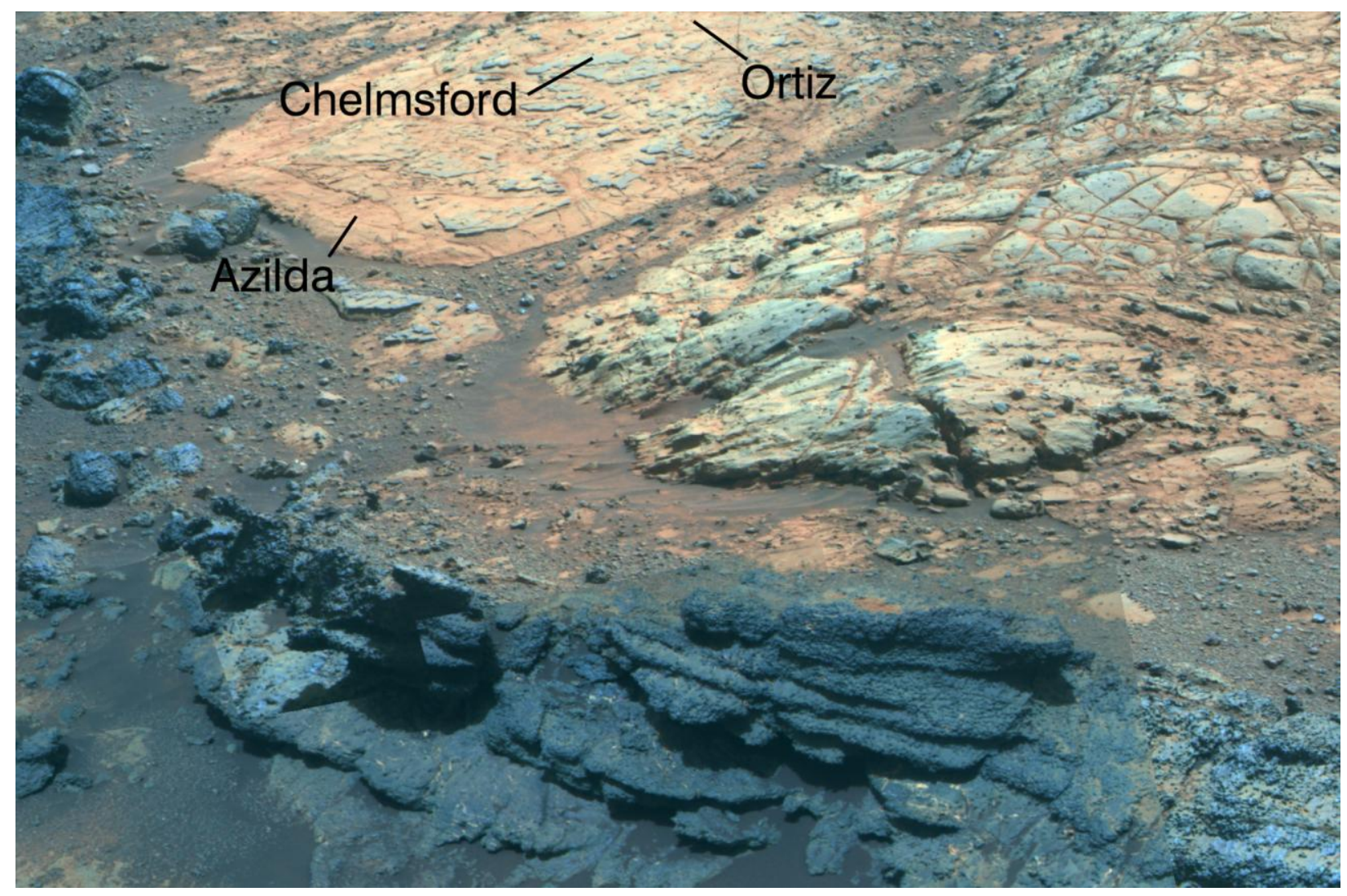

Figure 4 


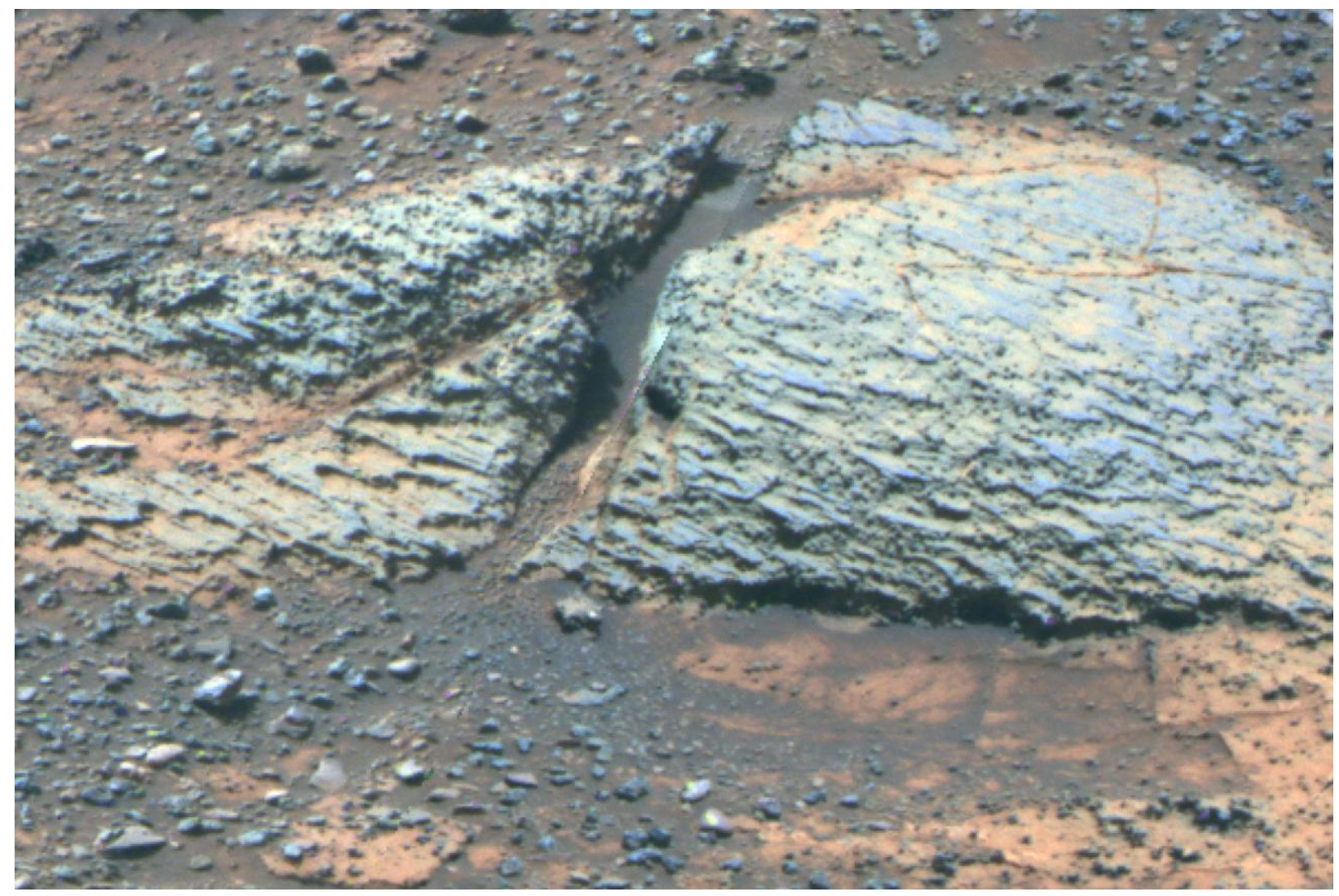

Figure 5 

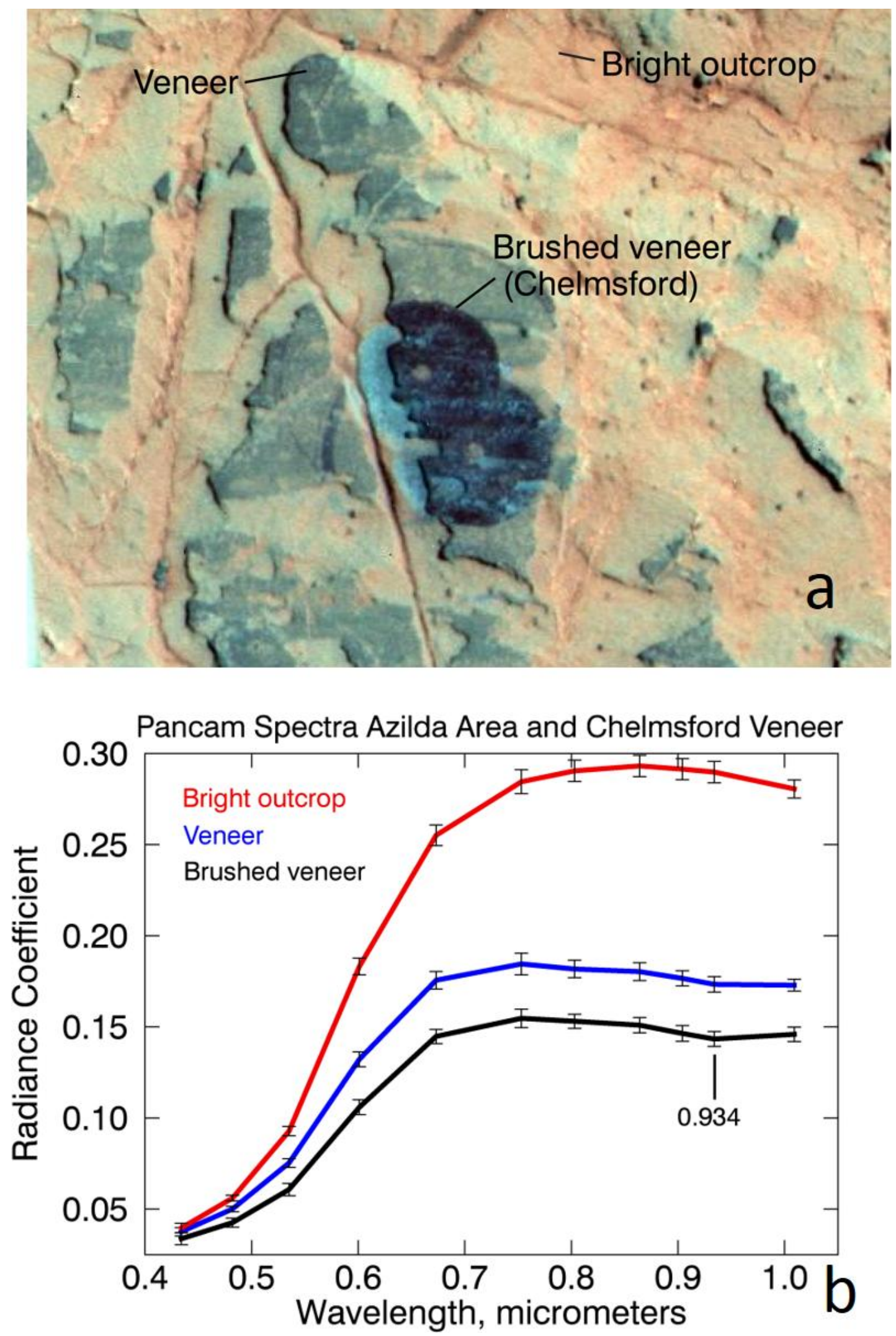

Figure 6 


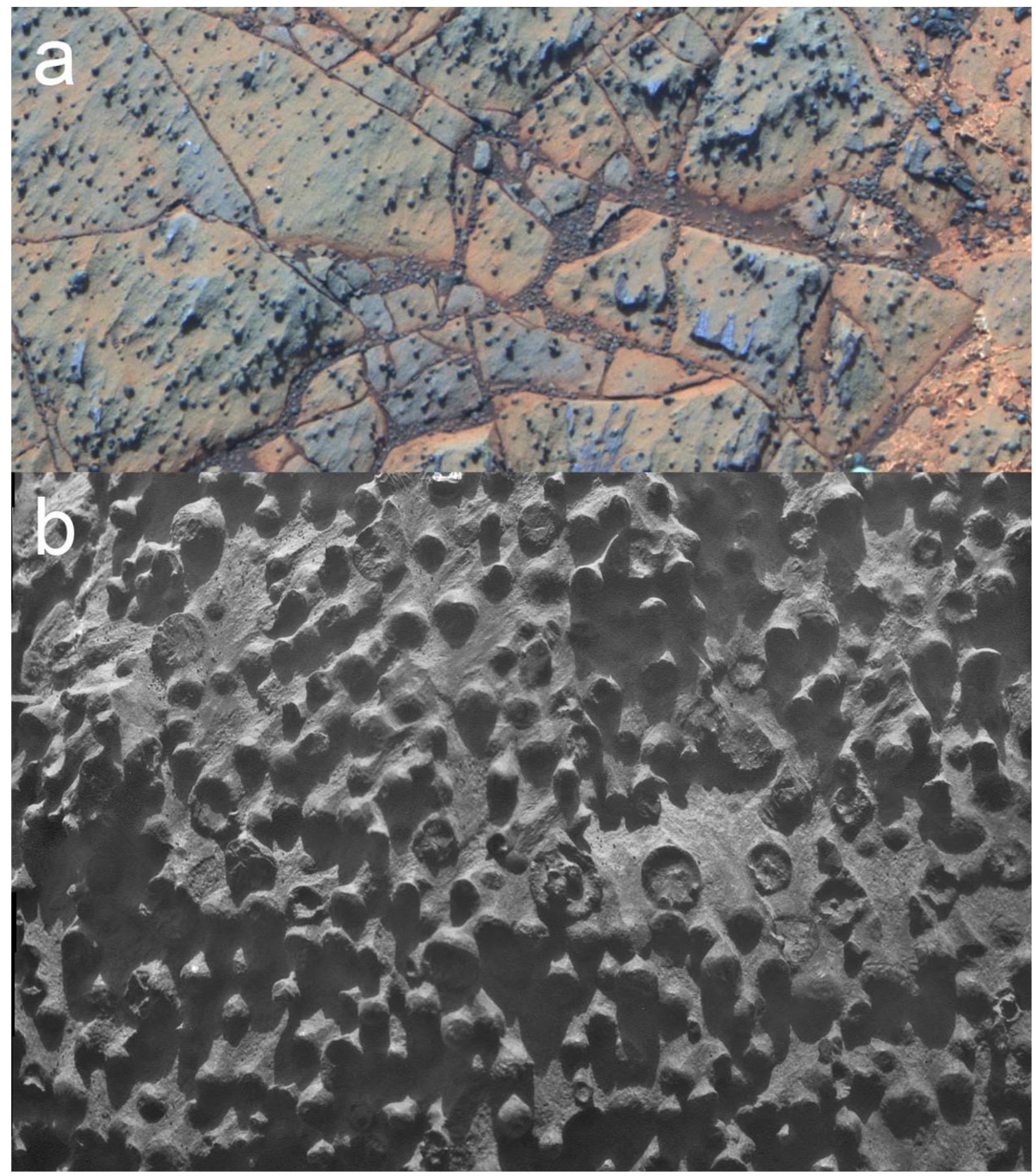

Figure 7 

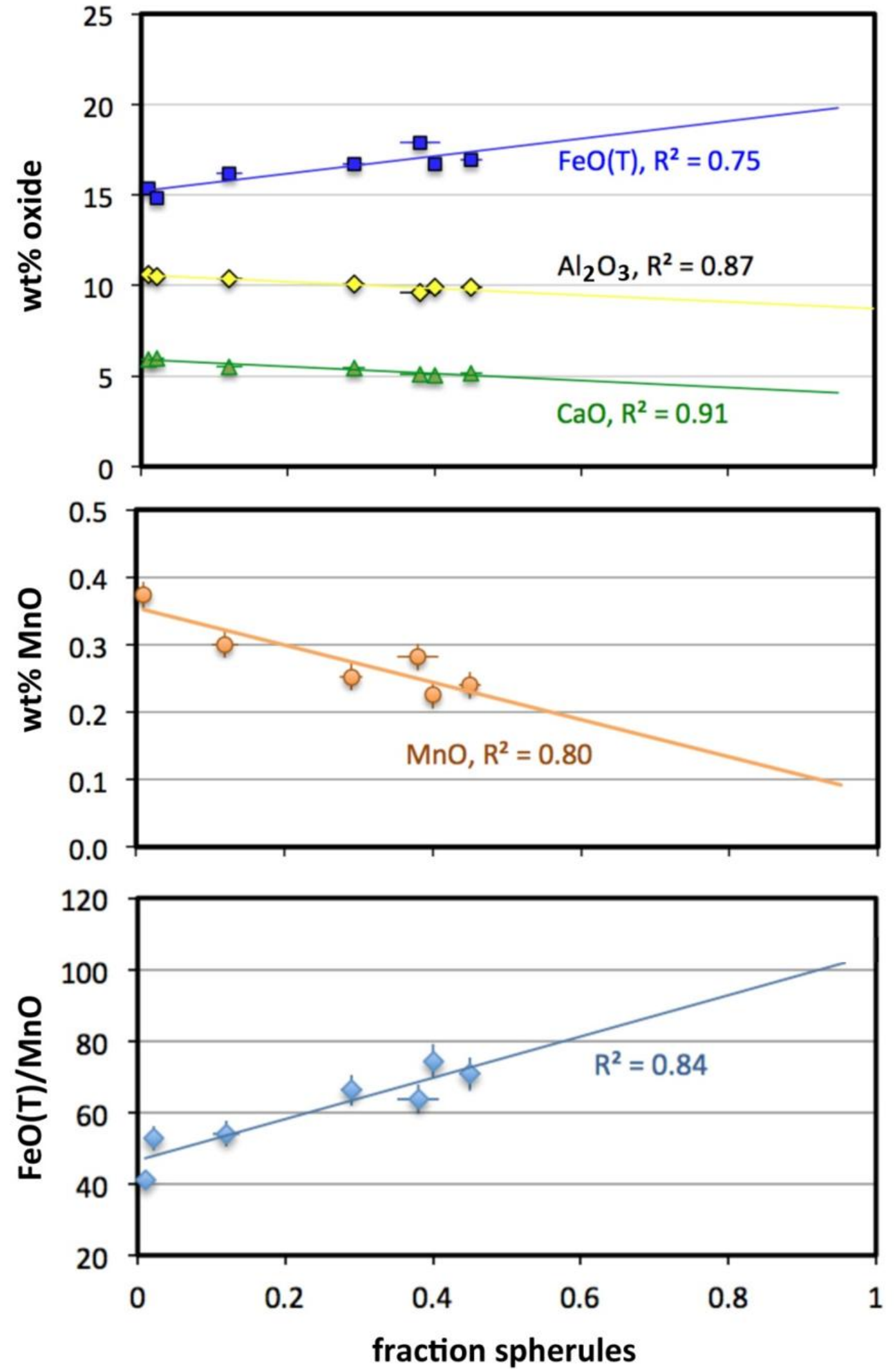

Figure 8 


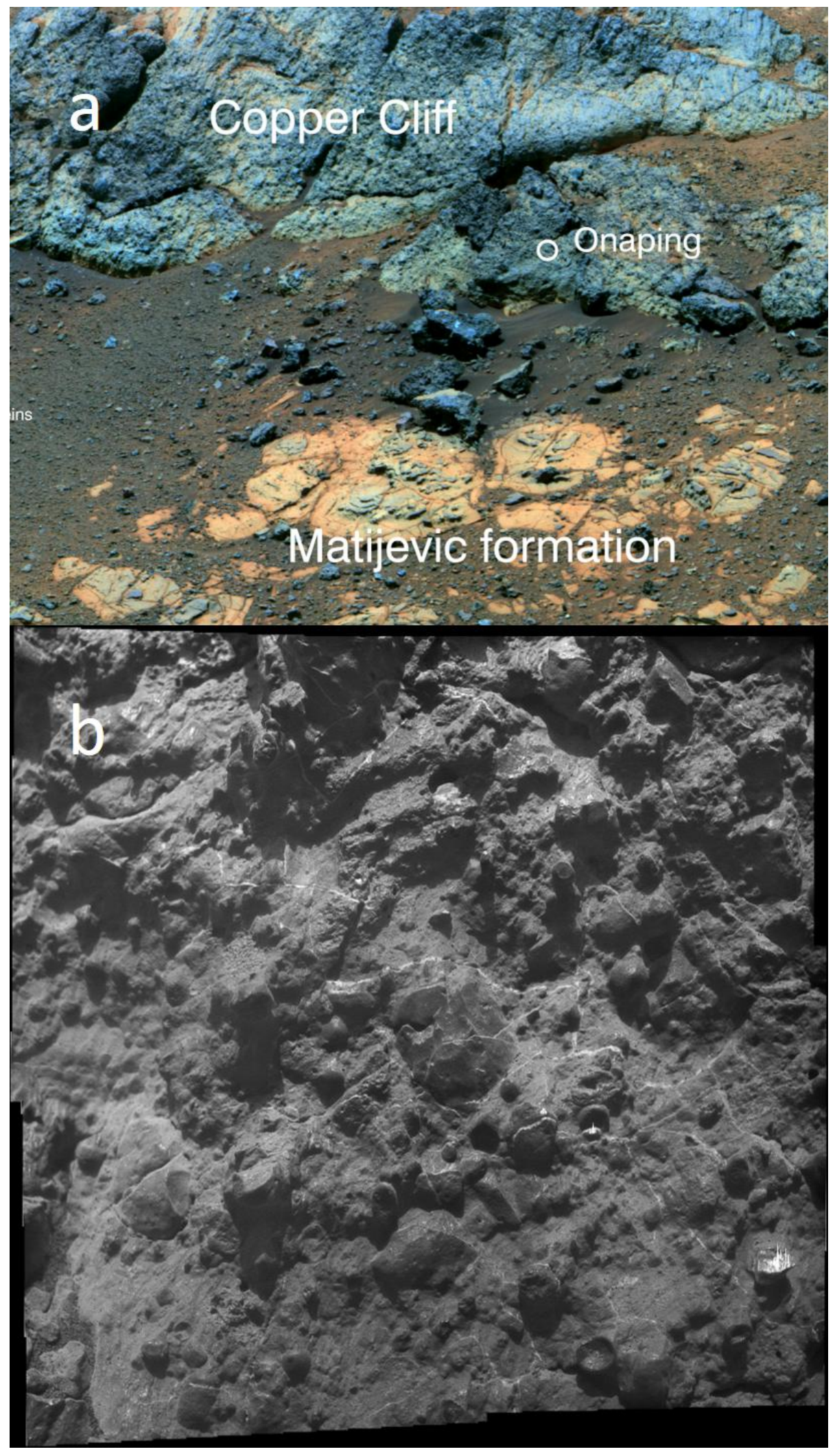

Figur e 9 


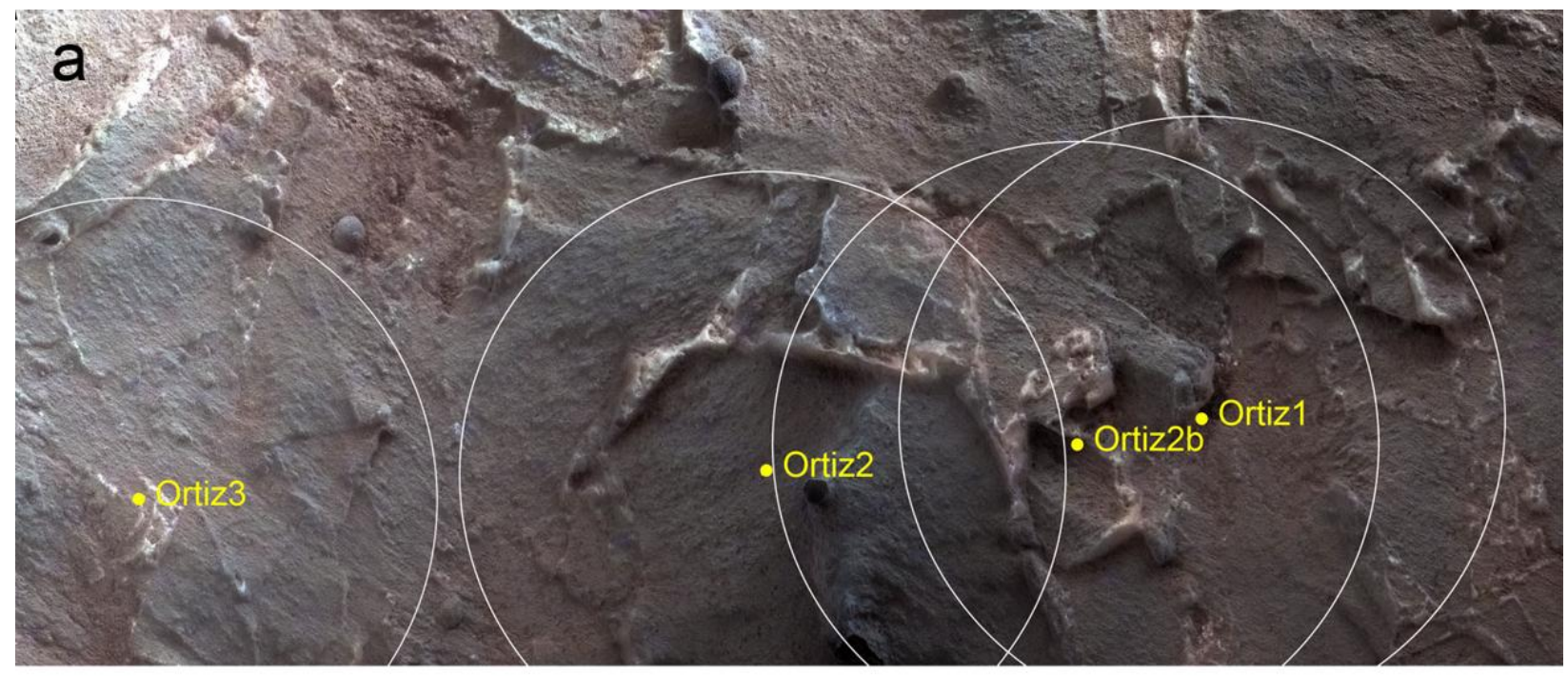

b

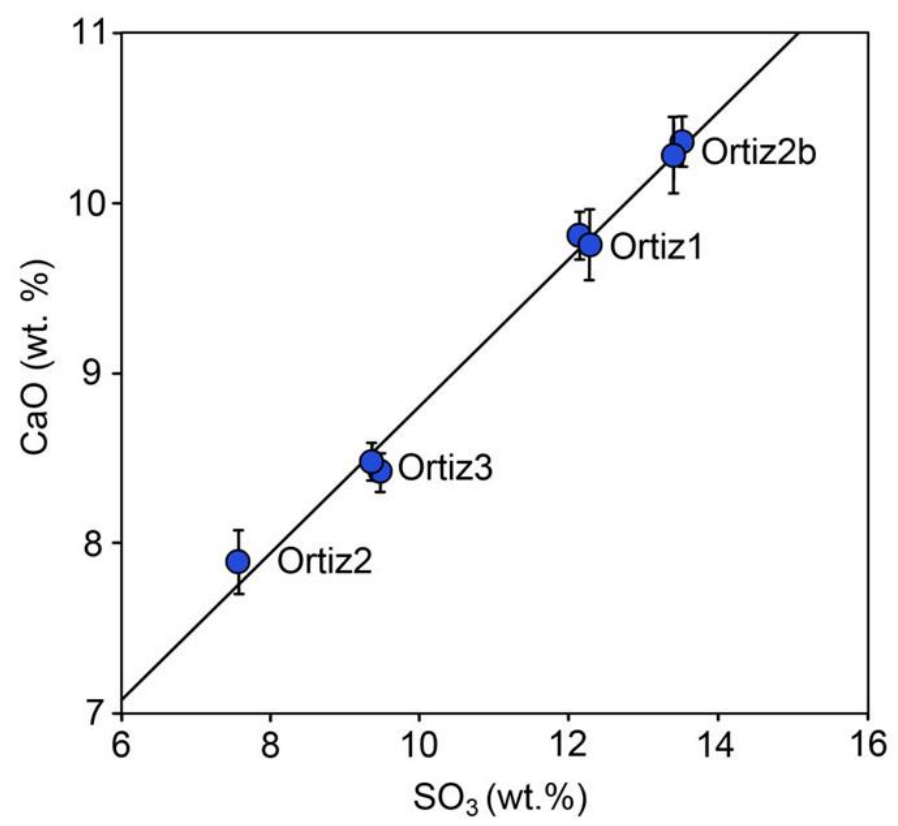

Figure 10 

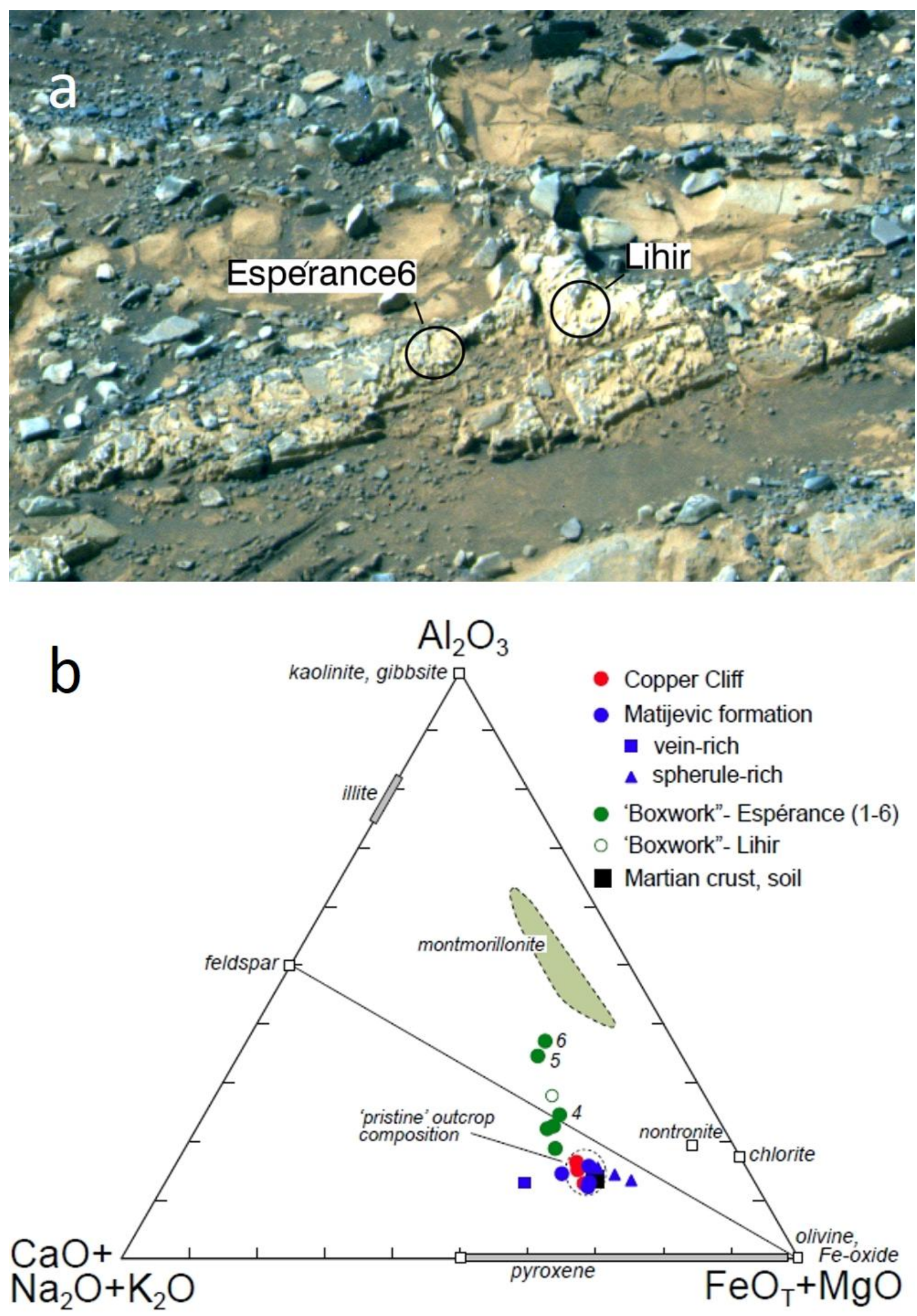

Figure 11 
Table 1. Elemental chemistry of selected samples as determined by the APXS instrument, under the standard assumption of a homogeneous APXS target matrix. $\mathrm{FeO}_{\mathrm{T}}$ denotes total iron oxides.

\begin{tabular}{|c|c|c|c|c|c|c|c|c|c|c|c|c|c|c|c|c|c|}
\hline \multirow{2}{*}{\multicolumn{2}{|c|}{ Sample }} & \multicolumn{13}{|c|}{ Weight Percent } & \multicolumn{3}{|c|}{$\mu g^{-1}$} \\
\hline & & $\mathrm{Na}_{2} \mathrm{O}$ & $\mathrm{MgO}$ & $\mathrm{Al}_{2} \mathrm{O}_{3}$ & $\mathrm{SiO}_{2}$ & $\mathrm{P}_{2} \mathrm{O}_{5}$ & $\mathrm{SO}_{3}$ & $\mathrm{Cl}$ & $\mathrm{K}_{2} \mathrm{O}$ & $\mathrm{CaO}$ & $\mathrm{TiO}_{2}$ & $\mathrm{Cr}_{2} \mathrm{O}_{3}$ & $\mathrm{MnO}$ & $\mathrm{FeO}_{\mathrm{T}}$ & $\mathrm{Ni}$ & $\mathrm{Zn}$ & $\mathrm{Br}$ \\
\hline MfLM & Azilda $^{1}$ & 2.55 & 7.91 & 10.60 & 51.2 & 1.50 & 2.47 & 0.53 & 0.28 & 5.98 & 0.87 & 0.24 & 0.36 & 15.4 & 922 & 134 & 48 \\
\hline MfLV & Sandcherry ${ }^{1}$ & 2.83 & 8.64 & 9.02 & 44.7 & 1.33 & 6.42 & 1.75 & 0.31 & 7.05 & 0.86 & 0.24 & 0.39 & 16.3 & 914 & 373 & 332 \\
\hline MfLM & Ortiz (no veins) & 2.21 & 6.58 & 9.62 & 46.5 & 1.23 & 7.87 & 0.92 & 0.32 & 7.91 & 0.92 & 0.23 & 0.47 & 15.1 & 723 & 193 & 157 \\
\hline MfLM & Ortiz2b (vein-rich) & 2.09 & 6.28 & 8.57 & 42.0 & 1.17 & 13.51 & 0.95 & 0.27 & 10.35 & 0.78 & 0.22 & 0.47 & 13.2 & 670 & 144 & 208 \\
\hline MfSR & Kirkwood $^{2}$ & 2.44 & 8.47 & 9.91 & 49.1 & 0.74 & 4.50 & 1.08 & 0.49 & 5.03 & 0.79 & 0.30 & 0.22 & 16.7 & 881 & 134 & 112 \\
\hline MfSR & Fullerton $^{2}$ & 2.25 & 8.22 & 10.47 & 50.1 & 0.89 & 4.64 & 0.85 & 0.33 & 5.81 & 0.96 & 0.29 & 0.28 & 14.7 & 738 & 176 & 159 \\
\hline MfSR & SturgeonRiver $^{1}$ & 2.21 & 9.29 & 9.61 & 49.5 & 0.59 & 3.32 & 0.47 & 0.36 & 5.11 & 0.81 & 0.36 & 0.29 & 17.9 & 1165 & 132 & 57 \\
\hline $\mathrm{CCB}$ & Onaping & 2.24 & 8.21 & 11.26 & 47.0 & 0.99 & 6.74 & 1.04 & 0.27 & 6.99 & 0.90 & 0.28 & 0.39 & 13.6 & 684 & 212 & 62 \\
\hline $\mathrm{CCB}$ & Vermilion Cliffs & 2.25 & 8.09 & 10.27 & 45.0 & 1.04 & 8.71 & 1.27 & 0.31 & 7.16 & 0.83 & 0.26 & 0.40 & 14.2 & 868 & 216 & 312 \\
\hline $\mathrm{CCB}$ & Vermilion Lake & 1.93 & 7.28 & 8.60 & 44.4 & 1.14 & 9.27 & 1.52 & 0.50 & 7.27 & 1.01 & 0.29 & 0.38 & 16.2 & 818 & 600 & 80 \\
\hline $\mathrm{CCB}$ & Maley $^{2}$ & 2.24 & 8.17 & 8.94 & 43.6 & 0.99 & 9.79 & 1.70 & 0.41 & 7.02 & 0.87 & 0.25 & 0.36 & 15.5 & 863 & 414 & 85 \\
\hline ESP & Espérance2 & 2.16 & 6.49 & 10.36 & 50.6 & 1.26 & 8.93 & 2.61 & 0.45 & 5.80 & 0.99 & 0.28 & 0.27 & 9.6 & 707 & 484 & 233 \\
\hline ESP & Espérance $6^{3}$ & 2.25 & 4.73 & 15.37 & 62.5 & 1.14 & 3.28 & 2.32 & 0.24 & 2.14 & 0.93 & 0.34 & 0.19 & 4.4 & 622 & 238 & 35 \\
\hline \multirow[t]{3}{*}{ ESP } & Lihir & 1.66 & 5.89 & 12.92 & 58.4 & 1.19 & 6.25 & 1.58 & 0.37 & 4.03 & 1.16 & 0.32 & 0.16 & 5.8 & 644 & 304 & 114 \\
\hline & Dark Soil ${ }^{4}$ & 2.34 & 7.33 & 9.65 & 47.0 & 0.85 & 4.68 & 0.59 & 0.51 & 7.38 & 0.90 & 0.39 & 0.39 & 17.6 & 349 & 199 & 24 \\
\hline & Average Error & \pm 0.21 & \pm 0.11 & \pm 0.13 & \pm 0.4 & \pm 0.08 & \pm 0.09 & \pm 0.02 & \pm 0.06 & \pm 0.05 & \pm 0.07 & \pm 0.03 & \pm 0.01 & \pm 0.1 & \pm 50 & \pm 20 & \pm 20 \\
\hline \multicolumn{3}{|c|}{ MfLM: Matijevic formation Matrix } & \multicolumn{15}{|c|}{ 1: Sample abraded using the RAT } \\
\hline \multicolumn{3}{|c|}{ MfLV: Matijevic formation Veneer } & \multicolumn{15}{|c|}{ 2: Sample brushed using the RAT } \\
\hline \multicolumn{3}{|c|}{$\begin{array}{l}\text { MfSR: Matijevic formation Spherule- } \\
\text { Rich }\end{array}$} & \multicolumn{15}{|c|}{ 3: Sample partially abraded using the RAT } \\
\hline \multicolumn{3}{|c|}{ CCB: Copper Cliff Breccia } & \multicolumn{15}{|c|}{ 4: Typical Meridiani basaltic sand composition } \\
\hline \multicolumn{18}{|c|}{ ESP: Espérance } \\
\hline
\end{tabular}




\title{
Supplementary Materials for
}

\section{Ancient Aqueous Environments at Endeavour Crater, Mars}

\begin{abstract}
Authors: R.E. Arvidson ${ }^{1}$, S.W. Squyres ${ }^{2}$, J.F. Bell III ${ }^{3}$, J. G. Catalano ${ }^{1}$, B.C. Clark ${ }^{4}$, L.S. Crumpler ${ }^{5}$, P.A. de Souza Jr. , A.G. Fairén ${ }^{2}$, W.H. Farrand ${ }^{4}$, V.K. Fox ${ }^{1}$, R. Gellert ${ }^{7}$, A. Ghosh ${ }^{8}$, M.P. Golombek ${ }^{9}$, J.P. Grotzinger ${ }^{10}$, E. A. Guinness ${ }^{1}$, K. E. Herkenhoff ${ }^{11}$, B. L. Jolliff ${ }^{1}$, A. H. Knoll ${ }^{12}$, R. Li ${ }^{13}$, S.M. McLennan $^{14}$,D. W. Ming ${ }^{15}$, D.W. Mittlefehldt ${ }^{15}$, J.M. Moore ${ }^{16}$, R. V. Morris ${ }^{15}$, S. L. Murchie ${ }^{17}$, T.J. Parker $^{9}$, G. Paulsen ${ }^{18}$, J.W. Rice ${ }^{19}$, S.W. Ruff ${ }^{3}$, M. D. Smith ${ }^{20}$, M. J. Wolff ${ }^{4}$
\end{abstract}

\footnotetext{
Affiliations:

${ }^{1}$ Dept. Earth and Planetary Sci., Washington University in Saint Louis, St. Louis, MO, 63130, USA.

${ }^{2}$ Dept. Astronomy, Cornell University, Ithaca, NY, 14853, USA.

${ }^{3}$ School of Earth and Space Exploration, Arizona State University, Tempe, AZ 85287, USA.

${ }^{4}$ Space Science Institute, Boulder, CO 80301, USA.

${ }^{5}$ New Mexico Museum of Natural History \& Science, Albuquerque, NM 87104, USA.

${ }^{6}$ CSIRO Computational Informatics, Hobart 7001 TAS, Australia.

${ }^{7}$ Department of Physics, University of Guelph, Guelph, ON, N1G 2W1, Canada.

${ }^{8}$ Tharsis Inc., Gaithersburg MD 20877, USA.

9 Jet Propulsion Laboratory, California Institute of Technology, Pasadena, CA 91109, USA.

${ }^{10}$ Division of Geological and Planetary Sciences, Caltech, Pasadena, CA 91125, USA.

${ }^{11}$ U.S. Geological Survey, Astrogeology Science Center, Flagstaff, AZ 86001, USA.

${ }^{12}$ Botanical Museum, Harvard University, Cambridge MA 02138, USA.

${ }^{13}$ Dept. of Civil \& Env. Eng. \& Geodetic Science, Ohio State University, Columbus, $\mathrm{OH} 43210$, USA.

${ }^{14}$ Dept. of Geosciences, State University of New York, Stony Brook, NY 11794, USA.

${ }^{15}$ ARES, NASA Johnson Space Center, Houston, TX 77058, USA.

${ }^{16}$ NASA Ames Research Center, Moffett Field, CA 94035, USA.

${ }^{17}$ Applied Physics Laboratory, Laurel, MD, 20723, USA.

${ }^{18}$ Honeybee Robotics \& Spacecraft Mechanisms Corporation, Pasadena, CA 91103, USA.

${ }^{19}$ Planetary Science Institute, Tucson, AZ 85719, USA.

${ }^{20}$ NASA Goddard Space Flight Center, Greenbelt, MD, 20771, USA.
}

correspondence to: arvidson@wunder.wustl.edu 
This PDF file includes:

Materials and Methods

Figs. S-1 to S-8

Table S-1 


\section{Materials and Methods}

\section{Processing of CRISM Data}

Geometric: The CRISM observation of interest for this paper (FRT0001D86B) was acquired over the northwestern side of Endeavour crater, including Cape York (Fig. S-1) (Table S-1). For the normal full resolution targeted (FRT) mode observations optics gimbal motions are set to acquire a series of incoming and outgoing emission phase function observations, together with a central scene when the instrument is at its closest approach to the surface target. Data are acquired in such a way for the central scene that pixels are approximately $18 \mathrm{~m}$ projected onto the surface, with little overlap. ATOs are acquired by commanding the gimbal control actuators to overlap the pixels in the alongtrack direction (Fig. S-2). This allows spatial sharpening of the resultant hyperspectral images in the along-track direction. We used a Tikhonov-based one dimensional regularization approach (45) to replace the overlapping pixels with the same number of pixels but regularly spaced and without overlap. This allowed recovery of $9 \mathrm{~m}$ pixels along track where overlap was densest. The procedure, which is basically a damped least squares approach, was applied on a column by column basis to regularize the cube. The regularized images were then map projected after the radiometric computations discussed in the next section were applied (Fig. S-3).

Radiometric: The I/F (scene radiance/solar radiance) values for the FRT0001D86B image cubes for $\mathrm{S}$ and $\mathrm{L}$ data (to $2.5 \mu \mathrm{m}$, longer wavelengths encounter saturated gas bands and thermal emission effects) were processed to single scattering albedos and recast to radiance coefficients for each spectral band before being spatially regularized and mapprojected. This was accomplished using the DISORT radiative transfer code (46) in which atmospheric dust and ice aerosols and gas bands $\left(\mathrm{CO}_{2}, \mathrm{CO}\right.$, and $\mathrm{H}_{2} \mathrm{O}$ vapor) were explicitly modeled (47). The surface was modeled using the Hapke photometric function (48) with a modestly backscattering single particle phase function (Table S-1). The retrieved single scattering albedos are formally defined as the optical scattering efficiency/(scattering+absorption efficiencies) and are dependent on grain size and optical constants and not lighting or viewing geometries. The spectra were retrieved by minimization of the sums of squares of deviations among the emission phase function observations and the central scene were the data sets overlapped. Atmospheric pressure was modeled based on local elevations and aerosol opacities were adjusted until the minimization was met. Gases were modeled using Correlated-K approaches (49).

CRISM L data require cooling of the detectors to achieve high $\mathrm{S} / \mathrm{N}$ and the coolers have been systematically degrading with time in terms of reaching set point temperatures. For example the reported detector temperature for FRT0001D86B is $-148^{\circ} \mathrm{C}$ whereas FRT0000CE1D used in (9) had a temperature of $-154^{\circ} \mathrm{C}$. The warmer temperatures lead to lower S/N and when combined with aging detectors this means that the retrieved SSA spectra are necessarily noisy and require recursive filtering as applied to the data shown in Fig. S-4. We note that for wavelengths longer than $\sim 2$ to $2.2 \mu \mathrm{m}$ the data are less noisy as compared to shorter wavelengths, as is evident from examination of the spectra. The 
reasons are several-fold. The on-board integrating sphere lamp blackbody emission peaks in these longer wavelengths, thus providing good signal for calibration purposes. There is also relatively low thermal background subtraction needed for the detectors. Finally, as shown in Fig. 16 of (3) this long wavelength region has the least high frequency spectral structure to the order sorting filter and this introduces the least amount of residual "hash" in the calibration and retrieval of $\mathrm{I} / \mathrm{F}$ values. The lower noise for the longer wavelengths is evident in Fig. S-4 and Fig. 2A and allows us to identify the $\mathrm{Fe}^{+3}$-rich smectite signature based on the $\mathrm{Fe}-\mathrm{OH}$ combination bands.

\section{Microscopic Imager Views of Azilda and $\underline{\text { Sandcherry Targets }}$}

The Microscopic Imager (MI) on the Instrument Deployment Device (IDD) acquires panchromatic images of target surfaces with $31 \mu \mathrm{m} /$ pixel spatial resolution (50). MI mosaics were acquired for multiple Whitewater Lake targets and we focus here on analysis of data for the Azilda bright layer after brushing with the Rock Abrasion Tool. The brushed Azilda target was imaged with the MI on sol 3076 as a 2 by 2 MI mosaic (Fig. S-5). The brushed area has a diameter of approximately $3.8 \mathrm{~cm}$. Due to the irregular nature of the surface not all of that area was brushed. The MI mosaic shows a valley protected from brushing and with lighting conditions that enhance fine surface details (Fig. S-6). Numerous sand-sized grains are evident, with sizes ranging from 0.14 to 0.20 $\mathrm{mm}$. Sand-sized grains are also evident in the brushed areas as positive relief and presumably more resistant features.

For the Sandcherry veneer target we show an MI-based anaglyph image generated using data acquired on sol 3137 at slightly different distances from the target, showing various parts of the target scene in good focus (Fig. S-7 and S-8). The MI focal sections were used to synthesize a stereo anaglyph using the technique described in (51). The smooth, somewhat pitted nature of the veneer surface is evident standing above the underlying bright layer. The spherule grains in the upper right portion of the image range in size from 1.6 to $2.9 \mathrm{~mm}$ across and are about the same height as the relief between the veneer and lower bright material. The bright material is sandstone, with particle sizes ranging from 0.10 to $0.14 \mathrm{~mm}$. This deposit is finer-grained than the Azilda bright material and exhibits embedded dark grains. 


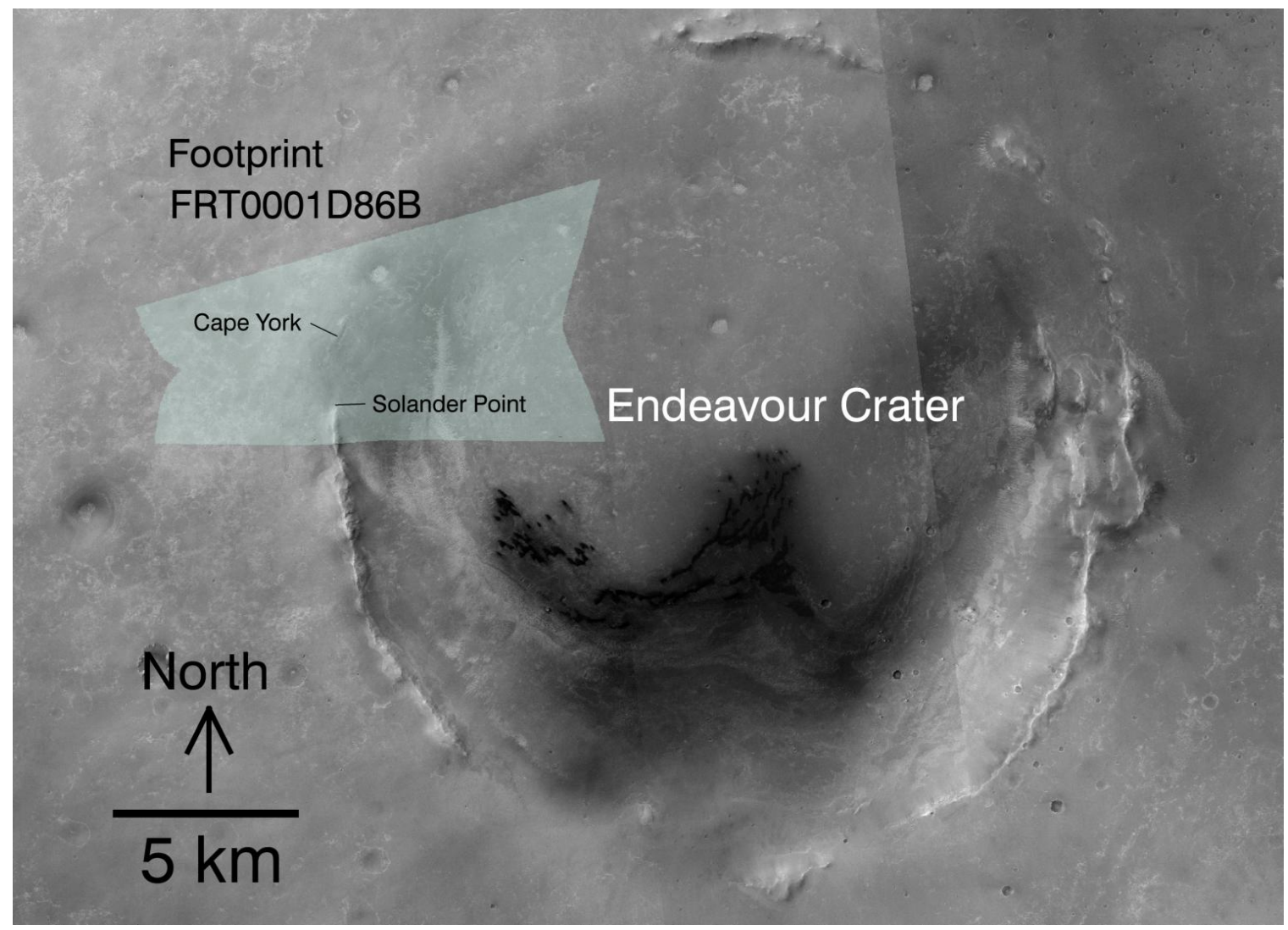

\section{Fig. S-1.}

Mosaic generated from Mars Reconnaissance Orbiter Context Imager observations to provide regional context for the CRISM observation analyzed in the paper. Endeavour is a highly degraded Noachian-aged impact crater largely buried by the Burns formation plains-forming sulfate-rich sandstones. Cape York is labeled and is an isolated crater rim segment. 


\title{
Solander Point
}

\section{Endeavour Crater Floor}

\author{
Nobbys Head
}

Meridiani Plains

\section{Highest Degree of Oversampling}

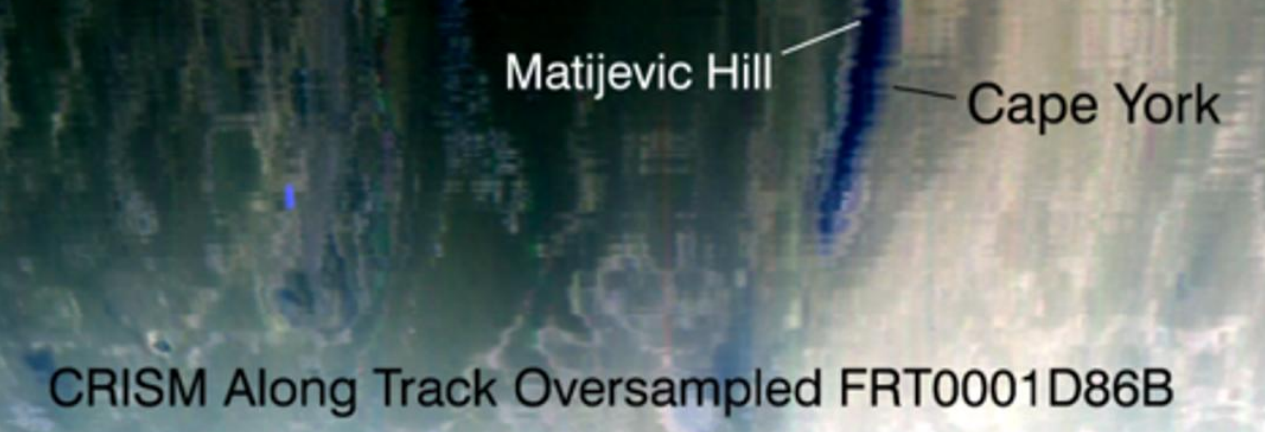

Fig. S-2

CRISM data are shown using the RGB color assignments described in Fig. 1, but displayed in sensor space geometry. CRISM is a line-scanning hyperspectral imager acquiring data while moving from south to north. Oversampling in the center of the scene leads to an elongated appearance of Cape York relative to its actual length. 


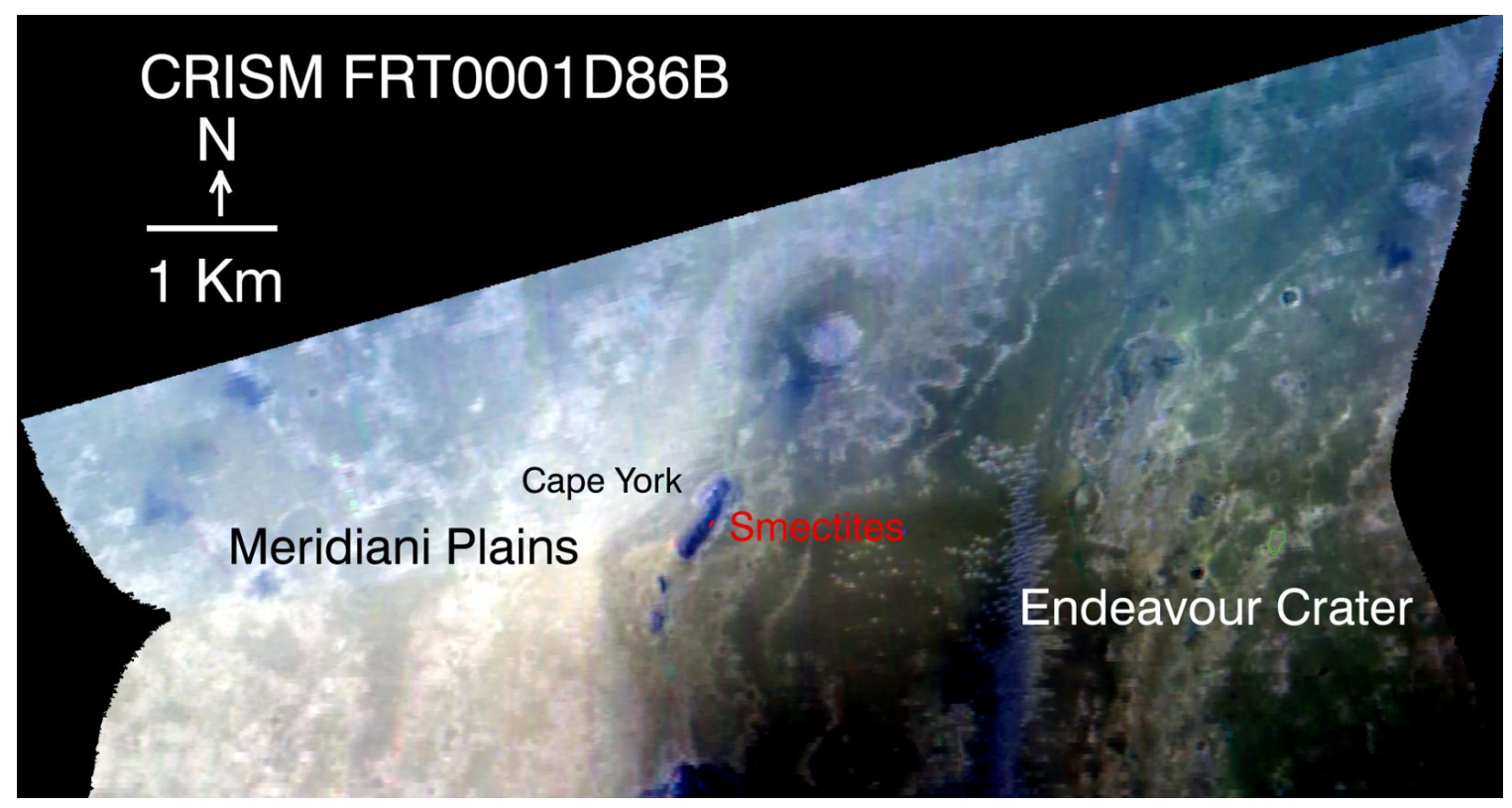

Fig. S-3

Regularized and map-projected version of the CRISM scene. Area with $\mathrm{Fe}^{+3}$-rich smectite signature on the eastern side of Cape York shown in enlarged form in Fig. 1. 


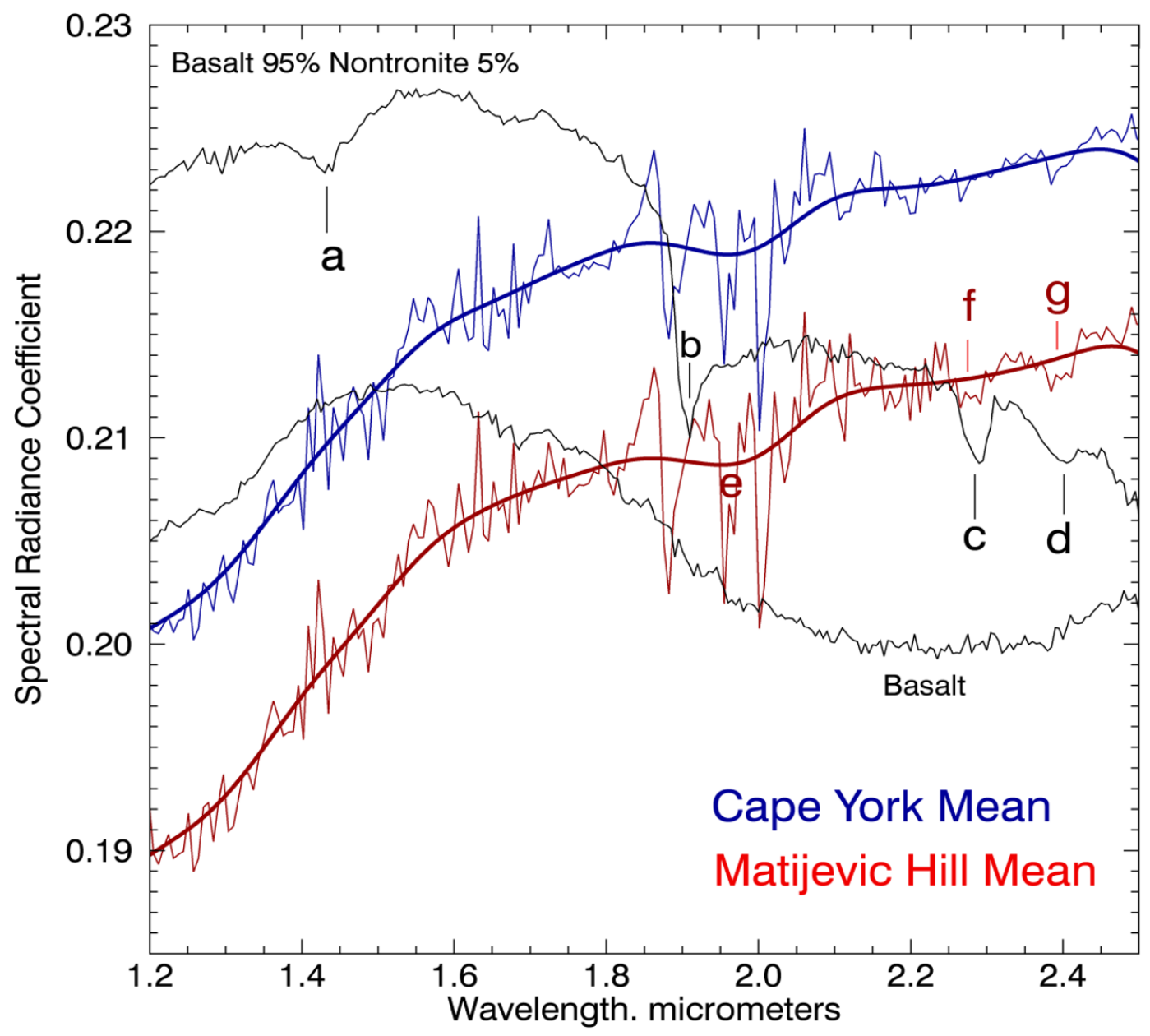

\section{Fig. S-4}

CRISM radiance coefficient spectra extracted for averages for pixels covering all of Cape York and the region for which the nontronite signature was found. Smooth curves through the CRISM data represent a recursive moving average in proportion to the overall noise level. The Cape York mean spectrum was multiplied by a factor of 1.3 relative to the Matijevic Hill mean spectrum to offset the two spectra for clarity. Also shown are laboratory spectra for basalt (spectrum dominated by pyroxene $\mathrm{Fe}^{+2}$ electronic transition absorptions) and basalt mixed with 5\% fine-grained nontronite (i.e., $\mathrm{Fe}^{+3}$-rich smectite) $(18,19)$, vertically scaled by a factor of 1.3 relative to the Matijevic Hill spectrum to overlap with the CRISM spectra. For the laboratory spectra an $\mathrm{OH}$ stretch overtone band is delineated by the letter a, and $\mathrm{OH}$ stretch and $\mathrm{H}-\mathrm{O}-\mathrm{H}$ bending mode combination absorption $\mathrm{b}$, whereas $\mathrm{c}$ and $\mathrm{d}$ delineate $\mathrm{OH}$ stretch and $\mathrm{Fe}-\mathrm{OH}$ bending mode combination absorptions. The absorption denoted by e in the smoothed CRISM spectra is the $\mathrm{OH}$ stretch and $\mathrm{H}-\mathrm{O}-\mathrm{H}$ combination band whose minimum is displaced to a longer wavelength relative to the basalt-nontronite spectrum because of the inability of the recursive filter to pick out the steep drop associated with this combination band. The $f$ and $\mathrm{g}$ letters delineate absorptions equivalent to the laboratory absorptions labeled as $\mathrm{c}$ and $\mathrm{d}$. The lack of $1.4 \mu \mathrm{m}$ absorptions and the similar shallow depths for the $1.9 \mu \mathrm{m}$ 
absorptions in the Cape York and Matijevic Hill spectra suggest desiccation of the $\mathrm{Fe}^{+3}$ rich smectite interlayer water signature $(16,17)$. 


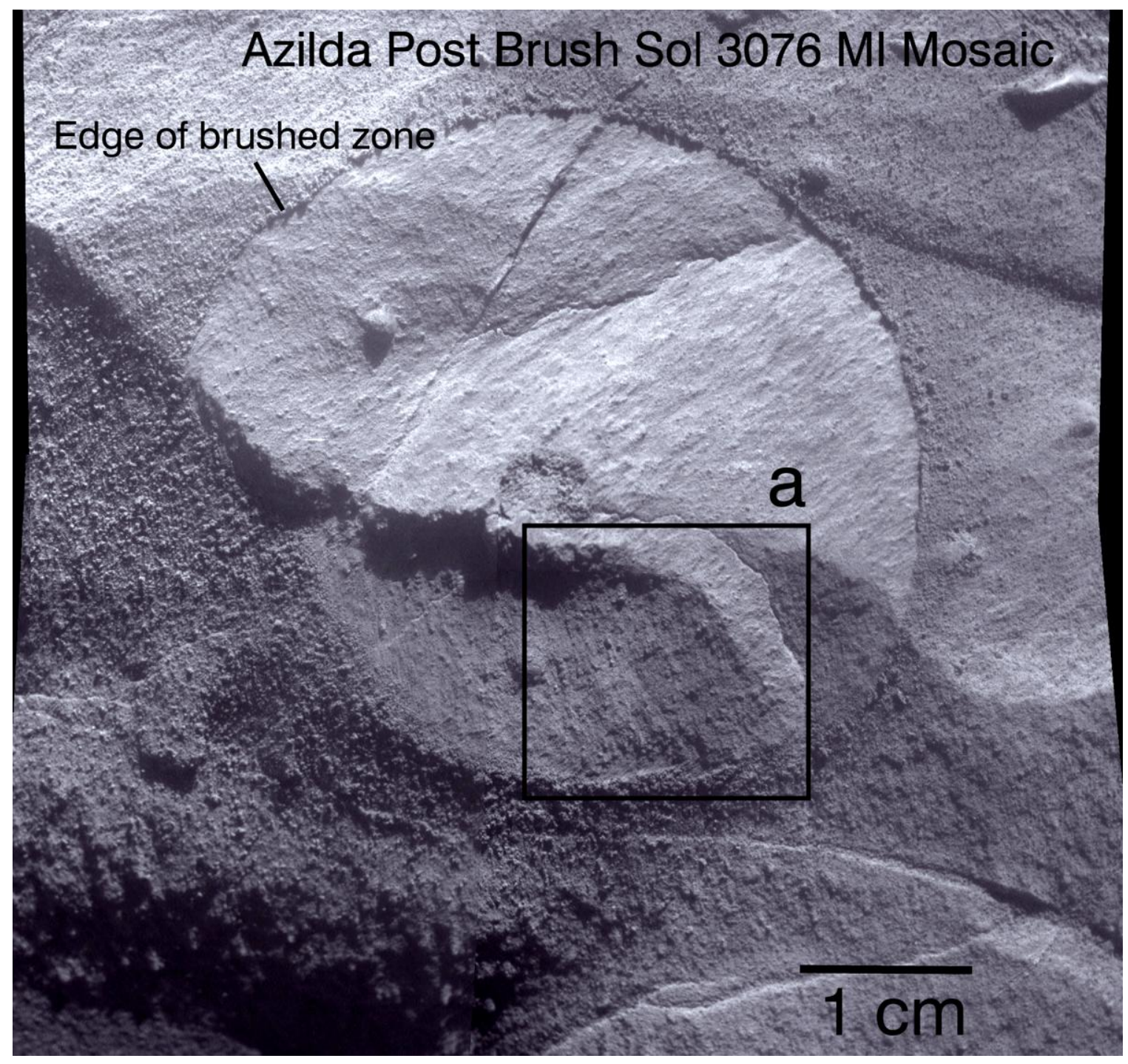

Fig. S-5

MI mosaic of the brushed Azilda surface. Opportunity is to the right of the mosaic. The data are shown rotated to better see textures in the box delineated by the letter A. Illumination from the top of the mosaic. 


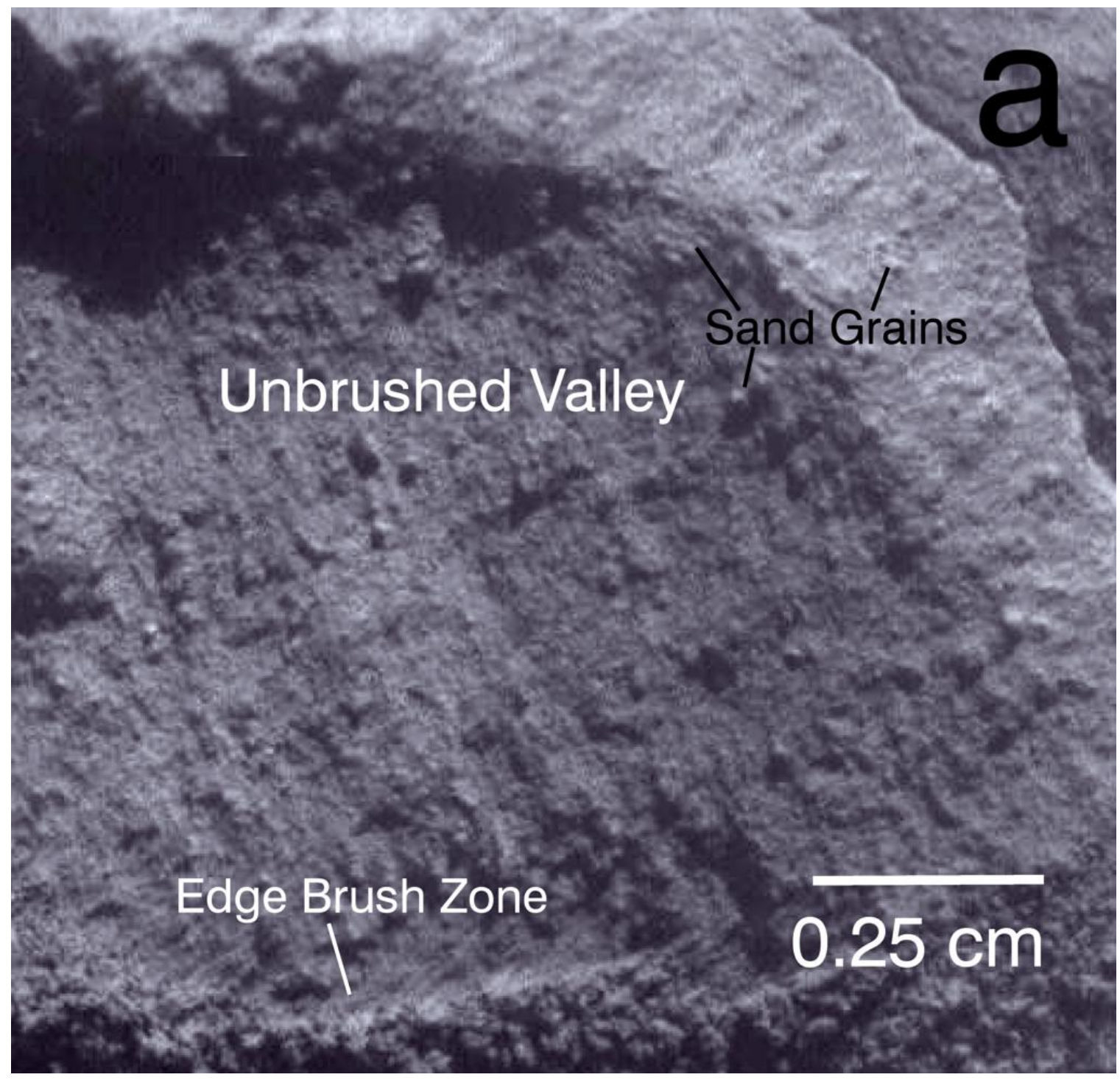

Fig. S-6

Enlargement of the MI for the box denoted by letter A in Fig. S-5. Note the numerous subrounded to rounded sand grains in the incompletely brushed portion of the image. 


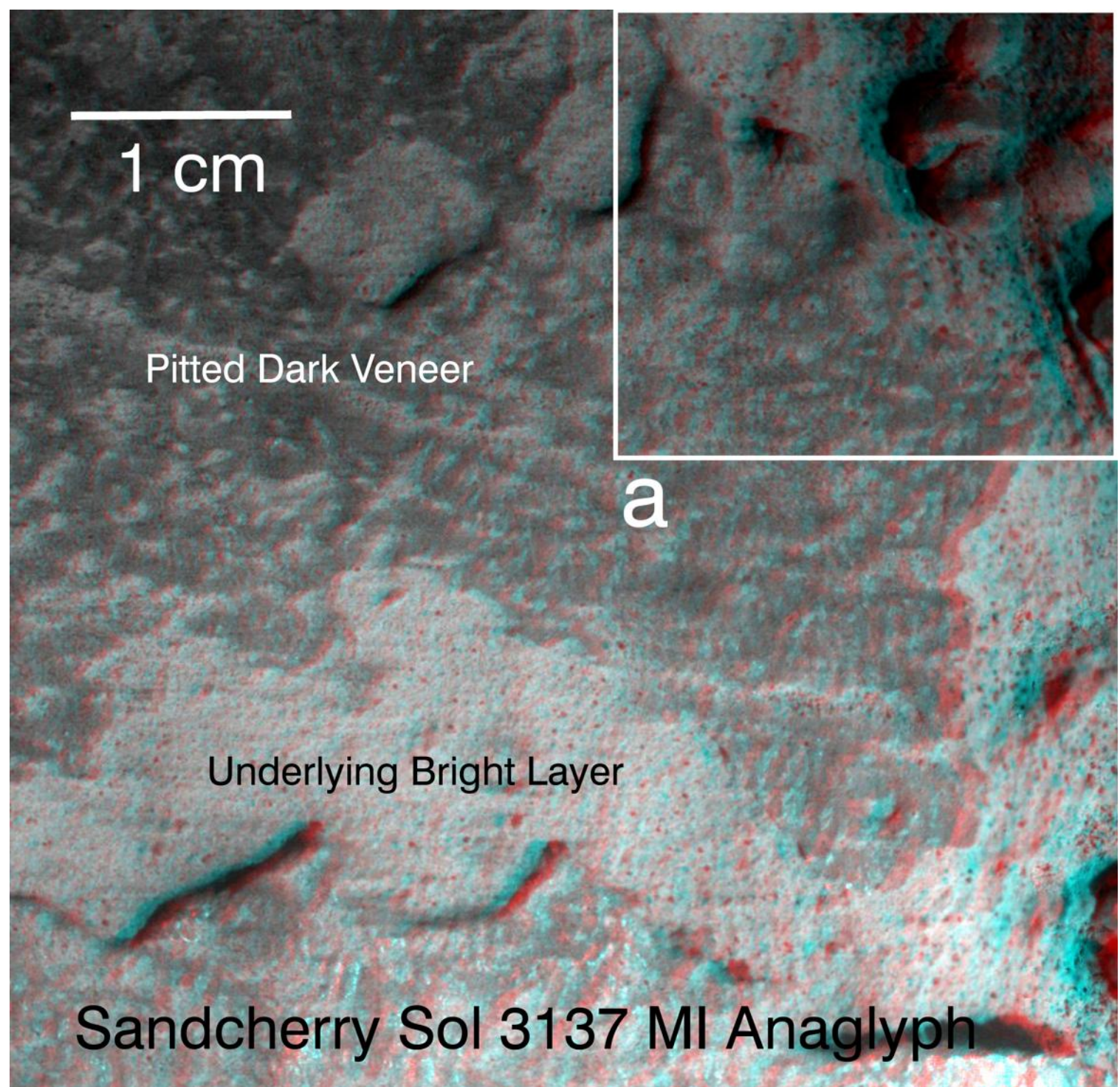

Fig. S-7

MI-based anaglyph for the Sandcherry veneer showing the planar but pitted nature of the veneer and the underlying bright sandstone. Pitting is interpreted to be due wind etching of the veneer. Rover located to the top of the frame. Illumination is from the lower right. 


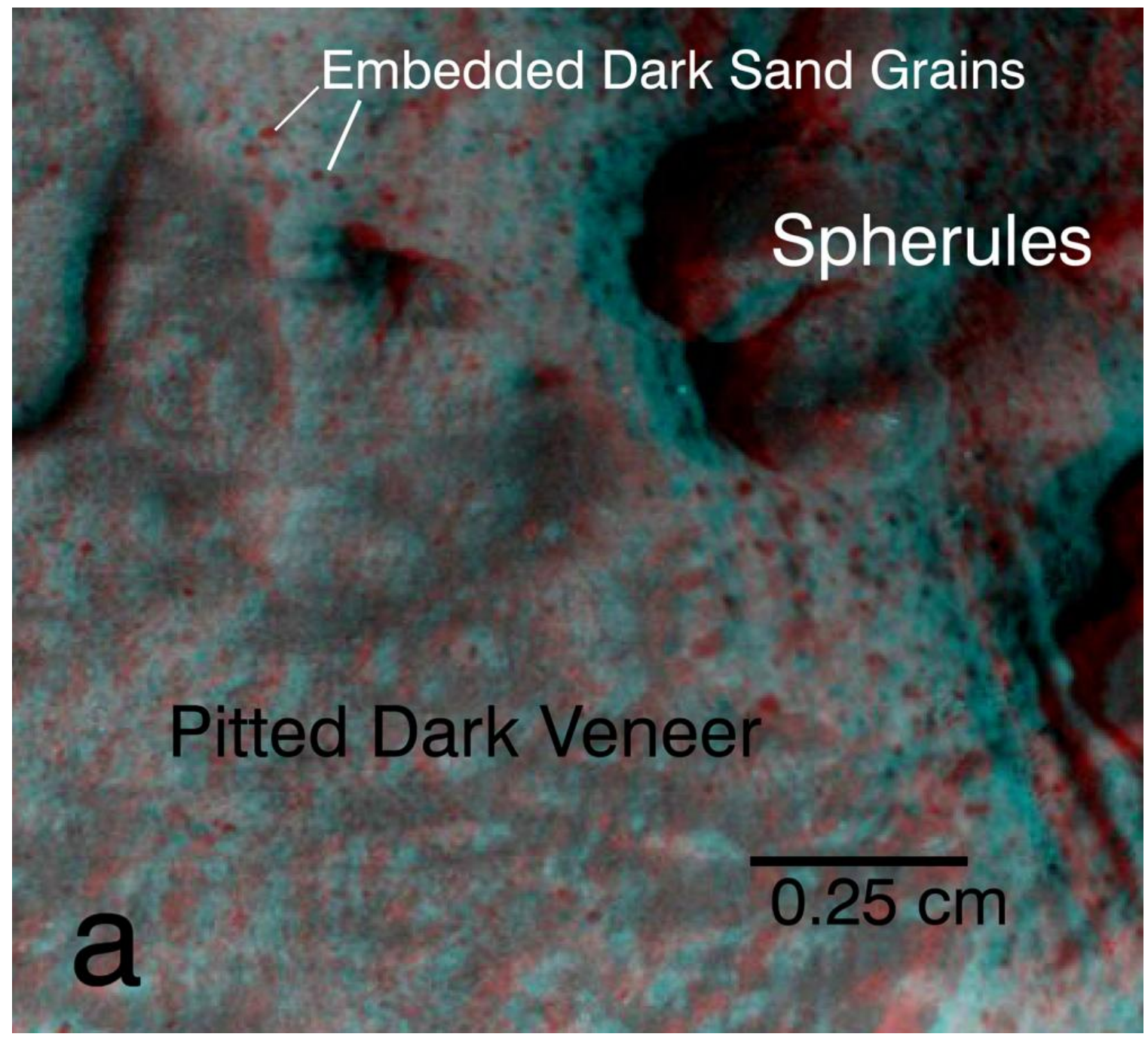

Fig. S-8

Enlargement of the boxed area denoted by letter A in Fig. S-7 showing embedded dark sand grains in the underlying sandstone, together with spherules with heights equivalent to the relief between the veneer and sandstone surface. 
Table S-1.

CRISM FRT0001D86B Observation and Processing Details

\begin{tabular}{|l|l|}
\hline Acquisition Date: & $3 / 28 / 2011$ \\
\hline Center Latitude: & $2.24^{\circ} \mathrm{S}$ (areocentric) \\
\hline Center Longitude: & $354.67^{\circ} \mathrm{E}$ (areocentric) \\
\hline Martian Season: & $\mathrm{Ls}=264^{\circ}$, late southern spring \\
\hline Retrieved Dust Aerosol Opacity: & 0.80 at a $0.9 \mu \mathrm{m}$ reference wavelength \\
\hline Retrieved Water Ice Aerosol Opacity: & 0.06 at $0.32 \mu \mathrm{m}$ reference wavelength \\
\hline Retrieved CO 2 Pressure for Central Portion of Scene: & 6.5 mbar \\
\hline $\begin{array}{l}\text { Retrieved Surface Photometric Function } \\
\text { Hapke Parameters: }\end{array}$ & $\begin{array}{l}\text { Henyey-Greenstein two term single particle } \\
\text { phase function asymmetry factor }=0.26, \\
\text { forward fraction }=0.30\end{array}$ \\
\hline
\end{tabular}

